
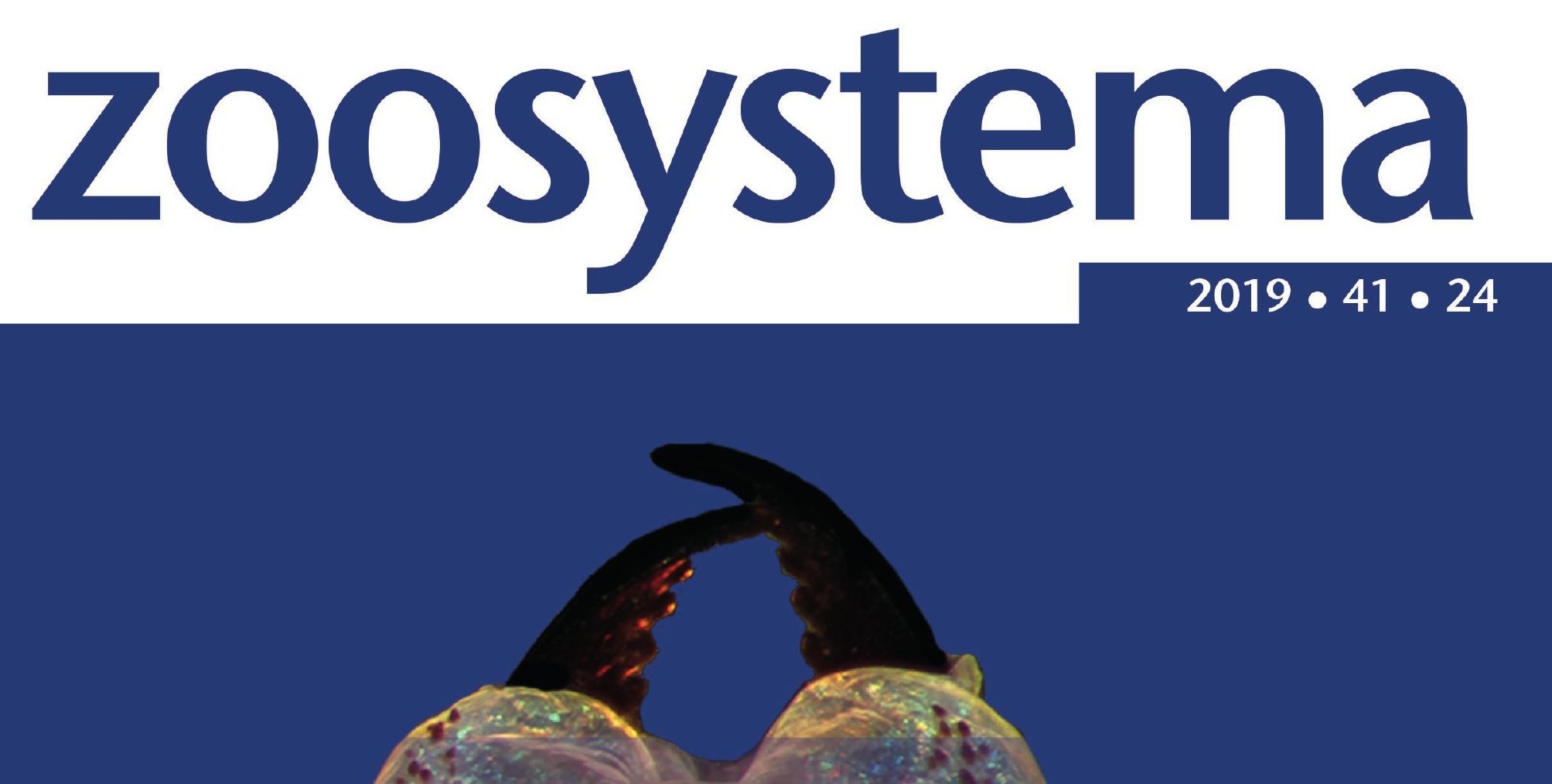

Redescription of two overlooked species of the Perinereis nuntia complex and morphological delimitation of $P$. nuntia (Savigny in Lamarck, 1818) from the Red Sea (Annelida, Nereididae)

Tulio F. VILLALOBOS-GUERRERO 
DiRECTEUR DE LA PUBLICATION: Bruno David

Président du Muséum national d'Histoire naturelle

\section{RÉDACTRICE EN CHEF / EDITOR-IN-CHIEF: Laure Desutter-Grandcolas}

ASSISTANTS DE RÉDACTION / ASSISTANT EDITORS: Anne Mabille (zoosyst@mnhn.fr), Emmanuel Côtez

\section{Mise en PAge / PAge LAYOUt: Anne Mabille}

COMITÉ SCIENTIFIQUE / SCIENTIFIC BOARD:

James Carpenter (AMNH, New York, États-Unis)

Maria Marta Cigliano (Museo de La Plata, La Plata, Argentine)

Henrik Enghoff (NHMD, Copenhague, Danemark)

Rafael Marquez (CSIC, Madrid, Espagne)

Peter $\mathrm{Ng}$ (University of Singapore)

Norman I. Platnick (AMNH, New York, États-Unis)

Jean-Yves Rasplus (INRA, Montferrier-sur-Lez, France)

Jean-François Silvain (IRD, Gif-sur-Yvette, France)

Wanda M. Weiner (Polish Academy of Sciences, Cracovie, Pologne)

John Wenzel (The Ohio State University, Columbus, États-Unis)

COUVERTURE / COVER:

Perinereis nuntia (Savigny in Lamarck, 1818), topotype (ZMB 4019-Q): pharynx, ventral view.

Zoosystema est indexé dans / Zoosystema is indexed in:

- Science Citation Index Expanded (SciSearch ${ }^{\circledR}$ )

- ISI Alerting Services ${ }^{\circledR}$

- Current Contents ${ }^{\circledR} /$ Agriculture, Biology, and Environmental Sciences ${ }^{\circledR}$

- Scopus ${ }^{\circledR}$

Zoosystema est distribué en version électronique par / Zoosystema is distributed electronically by:

- BioOne ${ }^{\circledR}$ (http://www.bioone.org)

Les articles ainsi que les nouveautés nomenclaturales publiés dans Zoosystema sont référencés par / Articles and nomenclatural novelties published in Zoosystema are referenced by:

- ZooBank ${ }^{\circledR}$ (http://zoobank.org)

Zoosystema est une revue en flux continu publiée par les Publications scientifiques du Muséum, Paris / Zoosystema is a fast track journal published by the Museum Science Press, Paris

Les Publications scientifiques du Muséum publient aussi / The Museum Science Press also publish:

Adansonia, Geodiversitas, Anthropozoologica, European Journal of Taxonomy, Naturae, Cryptogamie sous-sections Algologie, Bryologie, Mycologie.

Diffusion - Publications scientifiques Muséum national d'Histoire naturelle

CP 41 - 57 rue Cuvier F-75231 Paris cedex 05 (France)

Tél. : 33 (0)1 40794805 / Fax: 33 (0)1 40793840

diff.pub@mnhn.fr / http://sciencepress.mnhn.fr

(C) Publications scientifiques du Muséum national d'Histoire naturelle, Paris, 2019

ISSN (imprimé / print): 1280-9551/ ISSN (électronique / electronic): 1638-9387 


\title{
Redescription of two overlooked species of the Perinereis nuntia complex and morphological delimitation of $P$. nuntia (Savigny in Lamarck, 1818) from the Red Sea (Annelida, Nereididae)
}

\author{
Tulio F. VILLALOBOS-GUERRERO \\ El Colegio de la Frontera Sur, Departamento de Sistemática y Ecología Acuática, \\ Chetumal, Quintana Roo, 77014, México (Mexico) \\ tulio1786@msn.com
}

Submitted on 22 May 2018 | Accepted on 14 February 2019 | Published on 31 October 2019

KEY WORDS

Morphology, parapodia,

pharynx,

polychaete,

type material,

new synonyms,

Villalobos-Guerrero T. F. 2019. - Redescription of two overlooked species of the Perinereis nuntia complex and morphological delimitation of $P$. nuntia (Savigny in Lamarck, 1818) from the Red Sea (Annelida, Nereididae). Zoosystema 41 (24): 465-496. https://doi.org/10.5252/zoosystema2019v41a24. http://zoosystema.com/41/24

\section{ABSTRACT}

Two poorly-known species are systematically studied in detail: Nereis (Nereis) latipalpa Schmarda, 1861 from Cape Town, South Africa, and Nereis (Neanthes) larentukana Grube in Peters, 1881 from Larantuka, Flores, Indonesia. Both are raised from synonymy and transferred to the Perinereis nuntia species complex based upon the revision of type material using characters already known, novel, or even forgotten in the literature. Perinereis latipalpa n. comb. is different from its previous senior synonym P. vallata (Grube \& Kröyer in Grube, 1858) and related species. The type or topotype specimens of three other nereidid species share the same relevant features as P. latipalpa n. comb.; these are herein regarded as junior synonyms: Neanthes latipalpa Kinberg, 1865, Neanthes latipalpa typica Willey, 1904, and Perinereis namibia Wilson \& Glasby, 1993. Perinereis larentukana n. comb. is redescribed and compared to specimens of the morphologically similar species $P$. nuntia (Savigny in Lamarck, 1818). An improved characterization of P. nuntia using Red Sea specimens similar to the type description was also performed in order to clarify its morphology and restrict the speciescomplex name content. Other synonymized species of the $P$. nuntia complex were recognized as distinct: Perinereis brevicirris Grube, 1866, P. quatrefagesi Grube, 1878, and P. weijhouensis Wu, Sun \& Yang, 1981. This was based upon features not considered in the previous revisions but pointed out in the original descriptions. An identification key to the 20 currently valid species within the Perinereis nuntia complex is also provided. 


\begin{abstract}
RÉSUMÉ
Redescription de deux espèces négligées du complexe Perinereis nuntia et délimitation morphologique de P. nuntia (Savigny in Lamarck, 1818) de la mer Rouge (Annelida, Nereididae).

Deux espèces mal connues font l'objet d'une étude systématique détaillée : Nereis (Nereis) latipalpa Schmarda, 1861 de la ville du Cap, Afrique du Sud, et Nereis (Neanthes) larentukana Grube in Peters, 1881 de Larantuka, Flores, Indonésie. Toutes deux sont rétablies de leur statut de synonymes, et transférées dans le complexe d'espèces Perinereis nuntia en se basant sur la révision de matériel type et en utilisant des caractères déjà connus, nouveaux, ou mêmes oubliés dans la littérature. Perinereis latipalpa n. comb. diffère de son précédent synonyme senior $P$. vallata (Grube \& Kröyer in Grube, 1858) et des espèces apparentées. Les spécimens types ou topotypes de trois autres espèces de Nereididae partagent les mêmes caractères principaux que $P$. latipalpa n. comb. ; ils sont donc considérés ici comme des synonymes plus récents : Neanthes latipalpa Kinberg, 1865, Neanthes latipalpa typica Willey, 1904, et Perinereis namibia Wilson \& Glasby, 1993. Perinereis larentukana n. comb. est redécrite et comparée à des spécimens de $P$. nuntia (Savigny in Lamarck, 1818), espèce morphologiquement similaire. Une meilleure caractérisation de $P$. nuntia a également été réalisée à l'aide de spécimens originaires de la mer Rouge similaires à la description du type, afin de clarifier sa morphologie et de mieux délimiter le complexe d'espèces. D’autres espèces mises en synonymie dans le complexe P. nuntia ont été reconnues comme distinctes: Perinereis brevicirris Grube, 1866, P. quatrefagesi Grube, 1878, et P. weijhouensis Wu, Sun \& Yang, 1981, ceci sur la base de caractères non pris en compte dans les révisions précédentes mais signalés dans les descriptions originales. Une clé d'identification pour les vingt espèces actuellement valides dans le complexe Perinereis nuntia est également fournie.

synonymes nouveaux, combinaisons nouvelles.
\end{abstract}

\section{INTRODUCTION}

Perinereis Kinberg, 1865 is the second most species-rich nereidid genus that includes more than 80 valid species (Read \& Fauchald 2018). Although a review (Horst 1889) or regional studies (e.g. Rozbaczylo \& Castilla 1973; Hylleberg et al. 1986; Hutchings et al. 1991) have been undertaken, a complete revision of the genus is still imperative to delimit the morphology of all its species, and to obtain an accurate definition of Perinereis since it is polyphyletic (Bakken \& Wilson 2005).

Perinereis has been divided into different groupings based on a combination of the number of bars in pharyngeal Area VI and the expansion of dorsal ligule throughout the body (Hutchings et al. 1991). Among them, the group known informally as the Perinereis nuntia species complex (Wilson 1993; Wilson \& Glasby 1993) has been traditionally considered as a set of several varieties of $P$. nuntia (Savigny in Lamarck, 1818) (e.g. Augener 1913; Fauvel 1919, 1921, 1932, 1953). Nevertheless, several of them are currently regarded as valid species or synonymized with others (e.g. Bertrán 1980; Hylleberg et al. 1986; Hutchings et al. 1991; Wilson \& Glasby 1993). Wilson \& Glasby (1993) revised the accepted species of the $P$. nuntia complex, and the species have received particular attention ever since (Wilson 1993; Glasby \& Hsieh 2006; Park \& Kim 2007; Yousefi et al. 2011; Sampértegui et al. 2013).

Currently, the $P$. nuntia complex comprises 15 nominal species (Glasby \& Hsieh 2006). However, some species have been overlooked in the revision of the P. nuntia group (Wilson \& Glasby 1993) and in the subsequent studies; among them, two species historically referred as members of Neanthes Kinberg, 1865: Nereis (Nereis) latipalpa Schmarda, 1861 from Cape Town, South Africa, and Nereis (Neanthes) larentukana Grube in Peters, 1881 from Larantuka, Flores, Indonesia.

In the present study, the type materials of these two species were examined. Perinereis latipalpa n. comb. is herein reinstated, whereas three other species are regarded as junior synonyms: Neanthes latipalpa Kinberg, 1865, Neanthes latipalpa typica Willey, 1904, and Perinereis namibia Wilson \& Glasby, 1993. Likewise, the poorly known Indonesian species $P$. larentukana $\mathrm{n}$. comb. is redescribed and transferred to Perinereis after a detailed comparison of the original specimens with some individuals of the similar species P. nuntia (Savigny in Lamarck, 1818). Also, the latter species was characterized based on specimens from the Red Sea to restrict its morphology. An identification key to all species within the P. nuntia complex is provided.

\section{MATERIAL AND METHODS}

Type and non-type materials were examined in this study from several collections (see Abbreviations). Measurements of the specimens include total length, length to chaetiger 15, body width at chaetiger 15 excluding parapodia, and the total number of chaetigers. Paragnaths of each single area and both sides of paired areas were counted, as well as the number of teeth on the jaws; the range is also given (minmax). Paired paragnath areas were differentiated and reported as $a$ for left side and $b$ for right side of the specimens. The 
observation of features on non-everted pharynx required a longitudinal dissection in the mid-ventral oral region. Parapodia were dissected and mounted on glass slides to examine parapodial features.

Light microscopy observations were made using a stereomicroscope and a compound microscope. Specimens were photographed with a digital camera mounted on both the stereo- and compound microscopes, around 10-12 photos were assembled to improve the depth of field in the final figures using Helicon Focus ${ }^{\oplus} 6$ (method C) or by hand using Adobe Photoshop ${ }^{\oplus}$ CS6. Parapodia were illustrated in anterior views unless otherwise stated.

In the descriptions, the character data for the described specimen are given first, followed by values for the remaining examined material in brackets. The standardized terminology of nereidid parapodial features by Hylleberg et al. (1986) and modified by Bakken \& Wilson (2005), the nomenclatorial terminology for jaws by Jansonius \& Craig (1971), and for the pharynx and paragnaths by Bakken et al. (2009) were used. Likewise, the term "merged paragnaths" sensu Conde-Vela \& Salazar-Vallejo (2015) is applied to paragnaths fused at the base on area AIV, previously regarded as "smooth, parallel bars" sensu Wilson \& Glasby (1993) or "smooth bars" sensu Bakken et al. (2009), since a series of individual cones seems to be fused to shape the bars on area AIV of some Nereis (Conde-Vela \& Salazar-Vallejo 2015) and Neanthes (pers. obs.), but still further studies on the origin and shape of such paragnaths are needed.

Particular patterns on the shape of ridges and furrows of areas were recognized. Shape of ridges and furrows of AV depends entirely on the shape of those of AVI. For instance, the shape of the ridge and furrows of AV is altered by the shape holding furrows and both ridges of AVI. This areas AVI-V-VI pattern may form a $\lambda$-shaped furrow, i.e., the lateral dorsal ridges of the oral ring (AVIa and AVIb) are proximally separated from each other but coalescing submedially and distally forming a mid-dorsal inverted Y-shaped furrow (Area V) (Fig. 1A-C). This areas AVI-V-VI pattern may also be $\pi$-shaped, where the lateral ridges (AVIa and AVIb) are proximally and distally separated from each other but ridges splits sub-medially in different degrees (Fig. 1D-L; see below). In descriptions, the above mentioned arrangements of ridges and furrow are referred as "AVI-V-VI". They are diagnostic and used mainly to distinguish closely related species of $P$. nuntia complex. Areas pattern recognized in the species herein studied and related ones can be summarized as follows:

- $\lambda$-shaped: ridges of AVI distally and sub-medially coalesced, inverted ' $\mathrm{Y}$ ' furrow (Fig. 1A-C)

$-\pi$-shaped: ridges of AVI distally separated from each other

(Fig. 1D-L); subdivided as:

- $\chi$-shaped: ridges of AVI sub-medially (nearly) coalesced, concave furrows (Fig. 1D-F)

- v-shaped: ridges of AVI sub-medially markedly separated, parallel furrows (Fig. 1G-I)

- oc-shaped: ridges of AVI sub-medially markedly separated, concave furrows (Fig. 1J-L)
The relative extension of parapodial structures and the difference between the width and thickness of ligules and lobes follow that used in Villalobos-Guerrero \& Carrera-Parra (2015). The relative metric length in features concerning to dorsal cirrus and dorsal ligule is only used to measure the entire length of dorsal cirrus with the entire length of the distal and proximal lobes of dorsal ligule, which is not related to the relative length between the dorsal cirrus and the dorsal ligule. The distal one refers to the lobe of dorsal ligule projected distally from the base of dorsal cirri (Fig. 4E, black arrowhead), whereas the proximal refers to the upper edge of dorsal ligule placed between the base of parapodia and that of dorsal cirri (Fig. 4E, white arrowhead).

The length of some structures of the heterogomph falcigers were measured to relate proportions. Following Bakken \& Wilson (2005), the length of the blade at the proximal end (a) (Fig. 4K, black arrowheads) was compared with the length of the blade on the distal end (b) (Fig. 4K, white arrowheads). The species herein studied usually have medium heterogomph falcigers, i.e., the length of the distal end of the blade $(b)$ is longer than the length of the basal end of the same $(a)$ but shorter than twice its size $(\mathrm{a}<b<2 a)$; and rarely short heterogomph falcigers $(a \approx b)$. This proportion is represented in descriptions as $b / a=00-00$ times. According to Glasby \& Hsieh (2006), the length of the serrated region (Fig. 4L, black arrowheads) was compared with entire length of the blade (Fig. 4L, white arrowheads).

\section{ABBREVIATIONS}

\section{Institutions}

LACM-AHF Los Angeles County Museum of Natural History, Los Angeles, Allan Hancock Foundation, Polychaete Collection;

MNHN Muséum national d'Histoire naturelle, Paris;

MPW $\quad$ Museum of Natural History, Wroclaw;

NHMUK The Natural History Museum, London;

NMHW Natural History Museum, Vienna;

SMNH Swedish Museum of Natural History, Stockholm;

ZMB Museum für Naturkunde, Berlin.

\section{Measurements \\ TL Total length; \\ L15 length to chaetiger 15; \\ W15 body width at chaetiger 15, excluding parapodia.}

Features
AI
AIIa
AIIb
AIII
AIVa
AIVb
AV
AVIa
AVIb
AVII-VIII
AVI-V-VI
chaet
Mr
Or

Area I in maxillary ring of pharynx; left flank of area II in maxillary ring of pharynx; right flank of area II in maxillary ring of pharynx; area III in maxillary ring of pharynx;

left flank of area IV in maxillary ring of pharynx; right flank of area IV in maxillary ring of pharynx; area $\mathrm{V}$ in oral ring of pharynx;

left flank of area VI in oral ring of pharynx; right flank of area VI in oral ring of pharynx; area VII and VIII in oral ring of pharynx; areas VI-V-VI pattern in oral ring of pharynx; chaetiger; maxillary ring; oral ring. 


\section{SYSTEMATICS}

\section{Family NEREIDIDAE de Blainville, 1818}

Genus Perinereis Kinberg, 1865

Perinereis Kinberg, 1865: 175; 1910: 52.

TYPE SPECIES. - Perinereis novaehollandiae Kinberg, 1865, by subsequent designation (Hartman 1949). Currently regarded as a junior synonym of $P$. amblyodonta Schmarda, 1861 (Ehlers 1904; Hartman 1959), both described from Port Jackson, Sydney, Australia.

\section{Perinereis nuntia species complex}

Perinereis group 3 - Hutchings et al. 1991: 271.

Perinereis nuntia species group - Wilson \& Glasby 1993: 259. Glasby \& Hsieh 2006: 558.

Diagnosis (MOdified AfTer Glasby \& Hsieh 2006). - Prostomium with entire anterior margin, anterolateral edges wider than antennal diameter. Antennae present. Two pairs of eyes, anterior pair more widely spaced than posterior pair; lens anterolateral in anterior pair, posterolateral in posterior one. Palpophore with transverse groove present; palpostyles conical. Four pairs of tentacular cirri with distinct cirrophores. Apodous anterior segment, greater than length of chaetiger 1. Eversible pharynx with one pair of jaws, each with two or more canals emerging from pulp cavity. Both rings of pharynx with paragnaths, rarely absent on any of areas. Conical paragnaths on all areas, except AVI with 3-20 shield-shaped or pyramidal-shaped paragnaths on each side in a single row (sometimes few cones present); AIV occasionally with merged paragnaths. AVI-V-VI patterns: $\lambda$-shaped, $\chi$-shaped, $v$-shaped, or $0 c$-shaped. Notopodia with dorsal and median ligules from third parapodia. Dorsal cirri displacing progressively on dorsal ligule. Dorsal ligule similar in size and shape to median ligule throughout body or barely uneven. Notoacicular process present. Neuropodial postchaetal lobe poorly developed, rounded. Neuropodial superior and inferior lobes present at least in anterior parapodia, blunt. Ventral ligule present throughout body. Single ventral cirri throughout body. Notoaciculae and notochaetae on chaetigers 1 and 2, absent, thereafter present. Aciculae black. Notochaeta: homogomph spinigers, present throughout body. Neurochaeta, supracicular fascicle: homogomph spinigers and heterogomph falcigers, both present throughout body. Neurochaeta, subacicular fascicle: heterogomph spinigers present at least in median and posterior chaetigers, heterogomph falcigers present throughout body (homogomph spinigers rarely present). Anal cirri with cirrophore. Paired esophageal caeca present. Glandular patches present in dorsal ligule.

\section{REMARKS}

Grube (1851) referred all the known nereidids having biramous parapodia and three ligules in Nereis Linnaeus, 1758, which was simultaneously divided into three subgenera: Nereis (Heteronereis), $N$. (Nereilepas), and $N$. (Nereis). The latter subgenus, which included $N$. nuntia, was characterized by the species bearing long dorsal cirri (projecting beyond dorsal ligule). Later, Kinberg (1865) established several genera using the arrangement of areas and occurrence of papillae/paragnaths on the pharynx. For instance, he proposed Neanthes by having similar-sized parapodia throughout body and only conical paragnaths on all pharyngeal areas; whereas Perinereis Kinberg,
1865 by having parapodia progressively changing throughout body and pharynx with conical and transverse paragnaths, lacking pectiniform (or rod-like, sensu Bakken et al. 2009) paragnaths. However, Kinberg overlooked N. nuntia. Few years later, Ehlers (1868) lumped all Kinberg's genera with paragnaths in Nereis, and included $N$. nuntia in a group with similar-sized or slightly uneven parapodia throughout body and paragnaths on all areas. Afterward, Claparède (1870) separated a few species of Nereis in different subgenera.

Grube (1874) developed an accurate analysis of nereidids morphology, and despite the fact that he did not recognize several of the Kinberg's genera, including Neanthes, he suggested that Kinberg's classification of pharyngeal armament was useful for practical purposes. Thus, Grube (1874) proposed several subgenera of Nereis based on the occurrence of papillae and/or paragnaths on a single or both rings of pharynx; among them, $N$. (Lycoris) that was characterized by having only conical paragnaths on both rings. This subgenus was simultaneously divided into three groups mainly by the number and arrangement of paragnaths on AVI: 1) four or five paragnaths in quadrangle or cross, or more in a circular group (e.g. N. pelagica Linnaeus, 1758 and related species); 2) several paragnaths in a long single arched row, running towards the middle of AV (e.g. $N$. nuntia species complex); and 3) paragnaths in an oval or rounded patch of transverse rows, or a small linear transverse row of three cones (e.g. $N$. zonata Malmgren, 1867 and related species). Likewise, Grube (1874) also proposed $N$. (Perinereis) mainly by having AVI with 1-2 paragnaths transversely stretched. Later, von Marenzeller (1879) described a new species (Nereis mictodonta) related to $N$. nuntia-like species, and he stated that this group could not be included in the genus Perinereis nor Neanthes by sometimes having either conical and transverse paragnaths on AVI.

Langerhans (1880) recognized the generic level of Perinereis with no further details. Horst (1889), based mainly in Grube (1874), extended the $N$. (Perinereis) definition by including those species in which the AVI have either only transverse paragnaths, or both conical and transverse paragnaths. He included P. marionii (Audouin \& Milne-Edwards, 1833) and P. mictodonta, but $N$. nuntia was not mentioned. Later, de Saint-Joseph (1898) recognized as valid several of the Kinberg's names, either as genus or subgenus, based only on the pharyngeal characters, excluding all parapodial features. As a consequence, Perinereis was considered as valid only by the presence of conical and transverse paragnaths, whereas Neanthes was regarded as a subgenus of Nereis by having only conical paragnaths; nevertheless, it is noteworthy that $N$. nuntia was not considered in his proposal. Afterward, Gravier (1902) slightly improved the de Saint-Joseph's classification but recognized that it is still necessary a greater understanding of subgenera delimitation. Gravier $(1899,1902)$ proposed the inclusion of $N$. nuntia into $N$. (Neanthes) by having apparently only conical paragnaths, particularly on AVI; likewise, he supported Horst definition of Perinereis and described a new species ( $P$. heterodonta) with conical and transverse paragnaths on such pharyngeal area. The generic level and the 
expanded definition of Perinereis prevailed mainly within French annelidologists (de Saint-Joseph 1906; Fauvel 1911, 1914, 1918, 1919, 1921, 1932), whereas the subgeneric level and the older definition by Grube prevailed within German, Dutch and English annelidologists (Ehlers 1897, 1905, 1920; Augener 1913, 1918; McIntosh 1910; Horst 1924).

Augener (1913) suggested N. nuntia into N. (Perinereis), as for $N$. vallata Grube \& Kröyer in Grube, 1858 and his new subspecies $N$. (Perinereis) heterodonta var. mictodontoides. Afterward, Fauvel (1919) did not recognize the species closer to $P$. nuntia (known and valid at the moment), referring them only as varieties of $P$. nuntia. He regarded it as a polymorphic and widespread species distributed in the Red Sea, Persian Gulf, Indian Ocean, South Africa, Chile, Indo-Pacific, and Japan. Therefore, a general diagnosis of the species complex was provided for the first time, many species were synonymized, and several varieties arose from these assumptions: Perinereis nuntia var. brevicirris, $P$. nuntia var. djiboutiensis, P. nuntia var. heterodonta, P. nuntia var. vallata, and $P$. nuntia var. typica. The earlier species variety P. heterodonta var. mictodontoides Augener, 1913 and P. mictodonta were regarded as synonym of the brevicirris type (Fauvel 1919). Later, Fauvel (1921) proposed P. nuntia var. majungaensis from Madagascar, and kept recognizing the six varieties in further works.

Perinereis nuntia species complex has been retained in this genus ever since (Fauvel 1932, 1953; Hartman 1959; Day 1967; Paik 1975; Wu et al. 1985; Hutchings et al. 1991; Wilson 1993). Wilson \& Glasby (1993) developed a revisionary effort of the $P$. nuntia species complex using type and/or non-type materials of many related species. They provided a diagnosis for the complex, several species were recognized to species level, and others were regarded as synonyms; in total, 12 species were considered as valid within the complex. Later, Glasby \& Hsieh (2006) emended the P. nuntia species complex diagnosis, described three new related species and redescribed another two from the East Asia seas.

Based on phylogenetic analysis of nereidins using morphological data, Bakken \& Wilson (2005) established Perinereis as a polyphyletic group since their species were present in two distant clades. Some species, including the type species of the genus, $P$. novaehollandiae Kinberg, 1865, which is a junior synonym of $P$. amblyodonta (Schmarda, 1861), are nested with two Pseudonereis and three Neanthes species (currently regarded in Pseudonereis, sensu Bakken 2007); whereas the other three Perinereis species (P. variodentata, P. nuntia and $P$. vallata) were related with Neanthes/Nereis species. Despite this evidence, $P$. nuntia species complex is retained in Perinereis nowadays (Glasby \& Hsieh 2006; Park \& Kim 2007; Glasby 2015), although its morphology is notoriously different from the type species. For instance, according to Augener (1922) and my observations on some Australian specimens of $P$. amblyodonta (ZMB 5274), P. nuntia is mainly distinguished from $P$. amblyodonta by having dorsal ligule of similar size and shape or slightly uneven throughout the body, whereas in P. amblyodonta it is notoriously expanded in posterior parapodia. Likewise, the dorsal cirrus in $P$. nuntia is medially placed on dorsal ligule, but it is subterminal in posterior parapodia of $P$. amblyodonta. Finally, $P$. nuntia has a single transverse row of several $(\geq 3)$ shield-shaped bars and/ or conical (sometimes pyramidal) paragnaths on each side of AVI, whereas P. amblyodonta has one large shield-shaped bar on the same area.

This phylogenetic and morphological evidence suggests that the $P$. nuntia species complex belongs to a different genus, perhaps within the closely related genus Neanthes or Nereis; nevertheless, these two genera also undergo similar taxonomic problems since both are also regarded as polyphyletic (Bakken \& Wilson 2005). In order to elucidate the taxonomic problems, it is essential to restrict the definition of the genera by reviewing the species within. It would aid in delimiting their morphology, and consequently, in avoiding speculative new combinations, as could be the case of the P. nuntia species complex.

\section{Perinereis nuntia}

(Savigny in Lamarck, 1818), restricted

(Figs 1D-F; 2A-P)

Lycoris nuntia Savigny in Lamarck, 1818: 312-313. - Savigny 1822: 33, pl. 4, figs 2.1-2.10.

Nereis (Neanthes) nuntia - Gravier 1899: 237 (partim); 1902: 164167 (partim).

Perinereis nuntia - Ben-Eliahu 1991: appendix table 1. - Wilson \& Glasby 1993: 266-268, fig. 11a-g (partim). — Yousefi et al. 2011: 59, figs 2d, 7a-e (partim).

Perinereis nuntia typica - Fauvel 1919: 415-416 (partim); 1927: $432-$ 433 (partim); 1932: 109-110 (partim). — Ben-Eliahu 1972: 221.

Material examined. - Three specimens of Perinereis nuntia, ZMB 4019-Q, Red Sea, identified by A.E. Grube as Nereis nuntia, in poor conditions.

DiAGNOSIS. - Specimens with antennae nearly joined, nuchal organs subequal to posterior eyes, postero-dorsal tentacular cirri reaching chaetigers 4-6. Jaws with 2 canals. Maxillary ring: $\mathrm{AI}=1-3$; $\mathrm{AII}=9-11 ; \mathrm{AIII}=11-19$, two lateral cones; $\mathrm{AIV}=14-19$, merged paragnaths absent. Oral ring: AVI-V-VI pattern, $\chi$-shaped; $A V=2-4$, paragnaths behind AVI; $A V I=8-10$, arc long, oblique, bars short, even; AVII-VIII = 36-50, 4-5 transverse rows, proximal with smaller cones. Gap between AVI and AVII-VIII narrow. Dorsal cirri 3-4 times longer than dorsal ligule, inserted posteriorly on one-half of it. Dorsal ligule barely uneven throughout body, subequal to median ligule; distal lobe conical posteriorly. Ventral cirri cirriform. Homogomph spinigers with blades finely serrated, evenly spaced; absent in subacicular neurochaeta. Heterogomph spinigers with blades finely serrated, evenly spaced; present throughout. Heterogomph falcigers with medium and long blades.

HABiтAт. - Shallow waters, mud under rocks (Ben-Eliahu 1972, 1991).

TYPE LOCAlity. - Gulf of Suez (possibly Suez, Egypt, fide ÁlvarezCampos et al. 2015).

Distribution. - Gulf of Suez (Savigny 1822; Ben-Eliahu 1972, 1991); probably only in the Northern and Central Red Sea. 

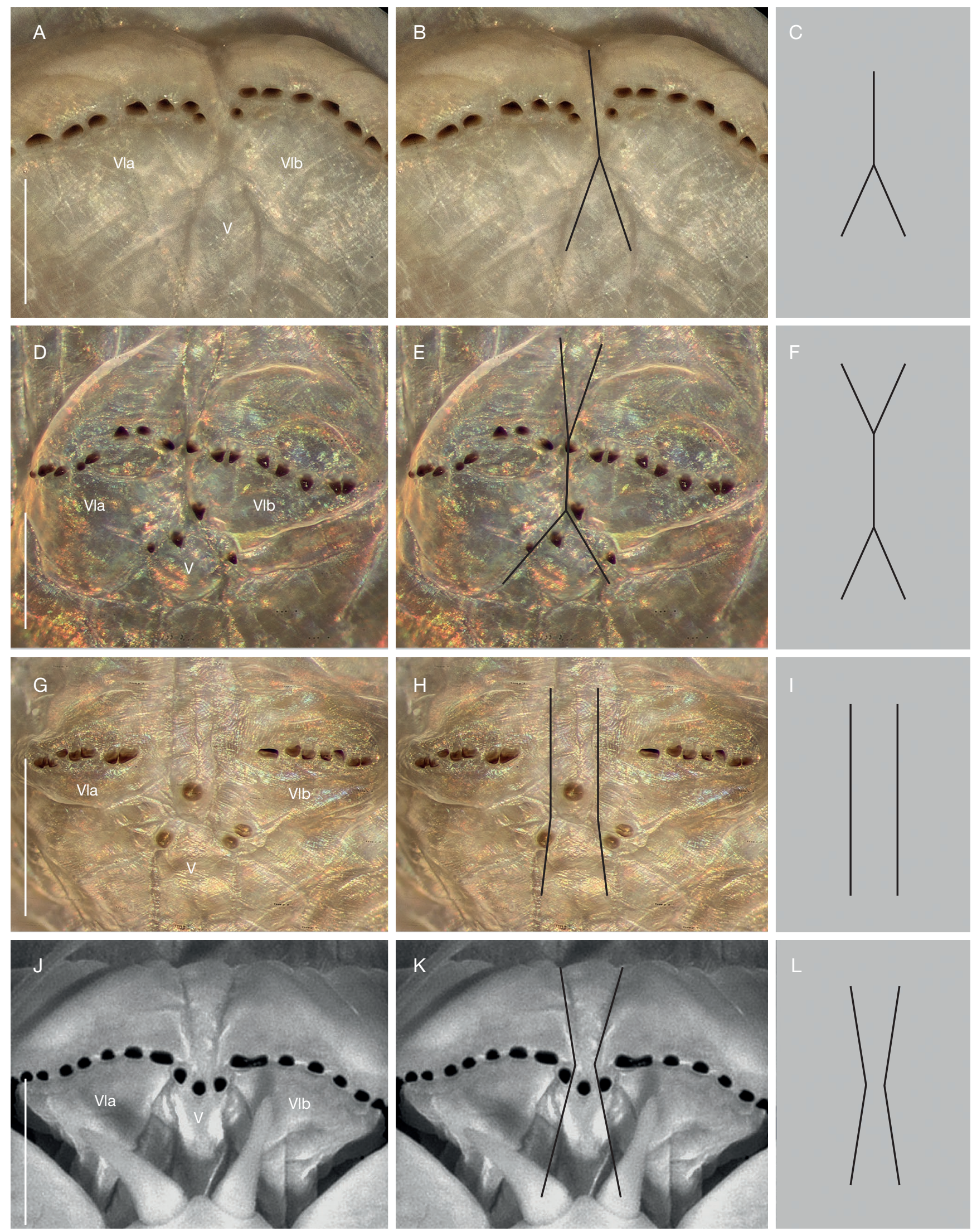

FIG. 1. - Areas VI-V-VI patterns of the pharynx shaped by the ridges and furrows: A-C, Perinereis latipalpa (Schmarda, 1861) n. comb. with a $\lambda$-shaped pattern; D-F, Perinereis nuntia (Savigny in Lamarck, 1818) with a x-shaped pattern; G-I, Perinereis larentukana (Grube in Peters, 1881) n. comb. with a u-shaped pattern; J-L, Perinereis shikueii Glasby \& Hsieh, 2006 with a oc-shaped pattern; A, D, G, J, dorsal portion of oral ring; B, E, H, K, same with a slightly irregular line drawings on the shape formed by AVI-V-VI pattern; C, F, I, L, symmetrical line drawings of the AVI-V-VI patterns. Scale bars: 1 mm. J, K, after Glasby \& Hsieh (2006). 


\section{DESCRIPTION}

Body. Non-type, ZMB 4019-Q, atoke female, complete, $\mathrm{LT}=220(135-220) \mathrm{mm}, \mathrm{L} 15=24(9.7-24) \mathrm{mm}, \mathrm{W} 15=4$ (2.2-4) mm, and 127 (109-127) chaetigers. Muscle almost completely digested, soft specimens. Body epidermal and glandular pigmentation completely faded.

Head. Prostomium sub-pentagonal, narrow anterior end (Fig. 2A); 1.3 times wider than long; anterolateral sides 2 times wider than antennal diameter. Palpophores oval (Fig. 2A), thick, as long as wide, nearly equaling entire length of prostomium; one deep wrinkle placed horizontally in distal third of palpophore. Antennae nearly joined, gap one-third of antennal diameter; digitiform, thickened, extending backward to nearly two-fifths of prostomium. Eyes and lens unpigmented due to long-term preservation, trapezoidal arrangement, anterior and posterior pairs separated (gap subequal to size of posterior; Fig. 2A); lens not visible. Anterior pair of eyes rounded, two-thirds width of antennal diameter. Posterior pair of eyes rounded, similarsized to anterior pair. Nuchal organs deeply embedded, slightly oblique, short, subequal to posterior eyes (Fig. 2A).

Apodous anterior segment \& tentacular cirri. Apodous anterior segment 4.7 (4.3-4.7) times wider than long, 1.4 (1.3-1.5) times longer than chaetiger 1 . Tentacular cirri pattern: Postero-dorsal cirri 1.7 times longer than antero-dorsal ones; anterior-ventral cirri two-thirds length of postero-ventral one. Antero-dorsal cirri reaching chaetiger 2 (2-3); antero-ventral three-quarters length of (or subequal to) palpophore. Postero-dorsal reaching chaetiger 4 (4-6); postero-ventral extending over prostomium to reach one-half of it. Cirrophores damaged, limp.

Pharynx. Everted between jaws only examined in one specimen, blackish in distal third, then brownish to yellow amber; 7 denticles, more or less developed, restricted to distal two-fifths of jaw, 1 denticle ensheathed proximally, inner margin of fang flattened, equaling next 2 (2-3) denticles; pulp cavity four-sixth length of jaw (Fig. 2B), distal apex not leveling denticles; 2 longitudinal canals emerging from pulp cavity (Fig. 2C). Maxillary ring (Fig. 2A, D, G): paragnaths conical, none worn, reddish amber colored, slightly smaller than those in oral ring. $\mathrm{AI}=1(1-3)$, slightly longer than the longest of AII (longitudinal regular line when $>2$ ). AIIa $=9$ (9-10), AIIb = 9 (9-11), oblique sub-oval patch, 2 (2-3) irregular rows. AIII = $11(11-19)$, rectangular (quadrangular or rectangular) patch, 2 (2-3) irregular transverse rows, two cones laterally isolated in each side. AIVa $=14(14-19), \mathrm{AIVb}=15$ (15-18), crescent-shaped patch, medial cones bigger, merged paragnaths absent. Oral ring (Fig. 2E-F): AVI-V-VI pattern, $\chi$-shaped; AVI overlapping proximally AV further behind arc of paragnaths (Fig. 2F). Paragnaths conical and shield-shaped bars, brownish amber (brownish amber or reddish amber) colored. $\mathrm{AV}=2$ (2-4), oblique (oblique or sub-triangular) patch, cones placed further behind from those on AVI, distal cone bigger. AVIa $=8(8-9)$, AVIb $=10(8-10)$, arc of paragnaths long, oblique (forming an obtuse angle with distal vertex), shield-shaped bars; bars short, tip campanulate or blunt, similar in length; ridges barely prominent, narrow, three-quarters width of palpophore. AVII-VIII = 36 (36-50), conical paragnaths, single band of 4 (4-5) transverse rows, increasing in number dorsoventrally from 2 to 4 (4-5) rows, distal rows with bigger cones, distal-most row regular, following two ones irregular because apparently mixed, proximal row slightly regular, smaller cones. Gap between AVI and AVII-VIII broad, as wide as palpophore (Fig. 2E).

Notopodia. Dorsal cirrus digitiform, longer than dorsal ligule throughout body; barely longer than ligule in first parapodia (Fig. 2H), 2 (1.5-2) times longer in anterior parapodia (Fig. 2I), 2.5 (2-3) times longer in median (Fig. 2J), 3 (3-4) times longer in posterior ones (Fig. $2 \mathrm{~K}$ ); cirrus longer than length of proximal lobe of dorsal ligule throughout body, much more longer from median parapodia (Fig. 2I-K); cirri inserted on one-third in anterior parapodia, two-fifths in median, one-half in posterior ones. Dorsal ligule somewhat uneven throughout body, becoming barely expanded from parapodia 88 (80-88); ligule 2.5 (2.2-2.5) times width of median ligule in posterior parapodia (Fig. 2K). Distal lobe of dorsal ligule bluntly conical in anterior parapodia, conical from median parapodia; distal lobe longer than proximal one in anterior parapodia, subequal to proximal in median, barely shorter in posterior ones. Dorsal ligule barely longer than median ligule in anterior parapodia (Fig. 2I), subequal to it from median ones (Fig. 2J, K). Glandular patches in dorsal ligule present but damaged by longterm preservation. Notopodial prechaetal lobe not developed.

Neuropodia. Neuracicular ligule shorter, 1.5 times wider than ventral ligule throughout body. Superior lobe blunt, shorter than inferior lobe throughout body, projecting beyond end of neuracicular ligule only in few first parapodia. Inferior lobe rounded, thickened, projected beyond end of neuracicular ligule in anterior parapodia, leveling it from median ones. Ventral ligule one-half (one-half or two-thirds) length of median ligule in anterior parapodia, three-quarters length from median ones, except in last parapodia, subequal to it. Ventral cirri cirriform, smaller than ventral ligule throughout body except in first parapodia, as long as it or barely longer.

Chaetae. Notochaetae with homogomph spinigers, blade finely serrated towards toothed edge, evenly spaced. Neurochaetal supracicular fascicle with homogomph spinigers and heterogomph falcigers, both present throughout; spinigers as notopodial ones (Fig. 2L), more numerous than falcigers in same fascicle; falcigers with medium blades $(b / a=1.37-1.74$ times), serrated region $0.42-0.53$ of total blade length (Fig. $2 \mathrm{~N}$ ). Neurochaetal subacicular fascicle with heterogomph spinigers and heterogomph falcigers, both present throughout; spinigers with blade finely serrated towards toothed edge, evenly spaced (Fig. 2M), less numerous than falcigers; falcigers with medium and long blades ( $b / a=1.56-2.15$ times $)$, serrated region $0.49-0.56$ of total blade length (Fig. 2O).

Pygidium. With short, slender anal cirri (Fig. 2P), as long as last 6 (6-7) chaetigers, cirrophores poorly developed. 

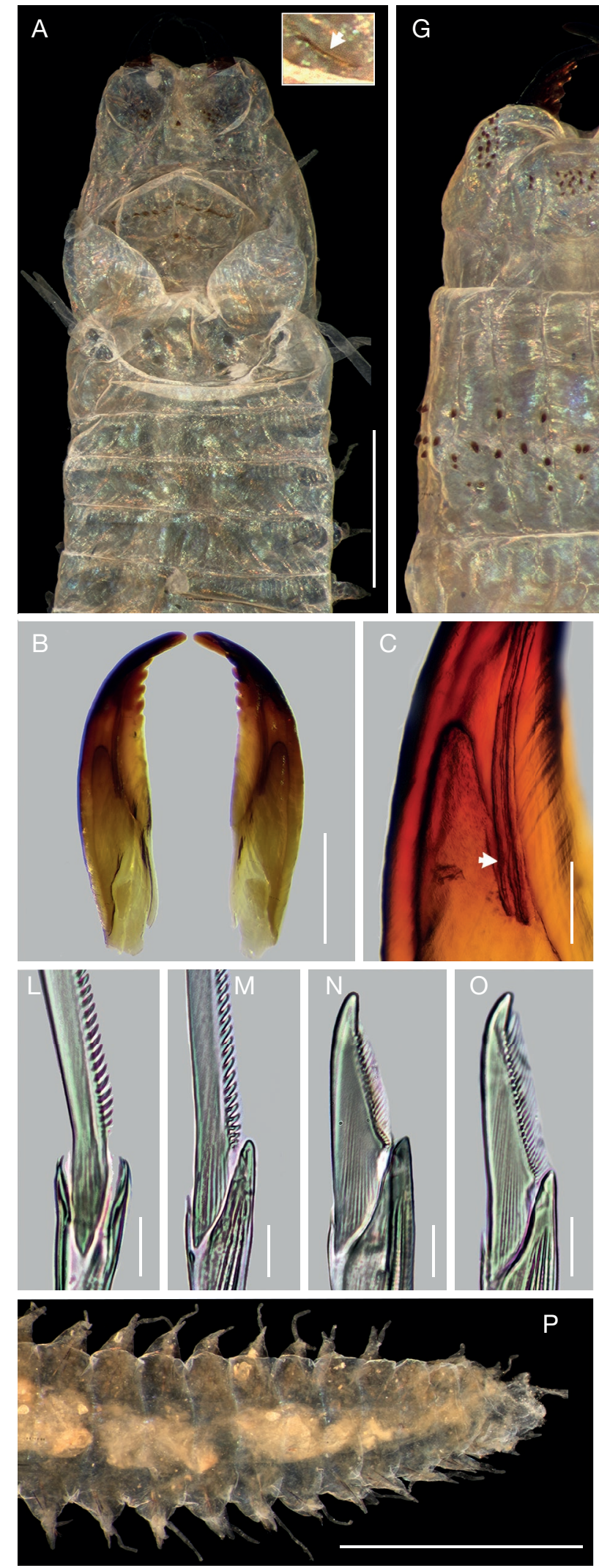
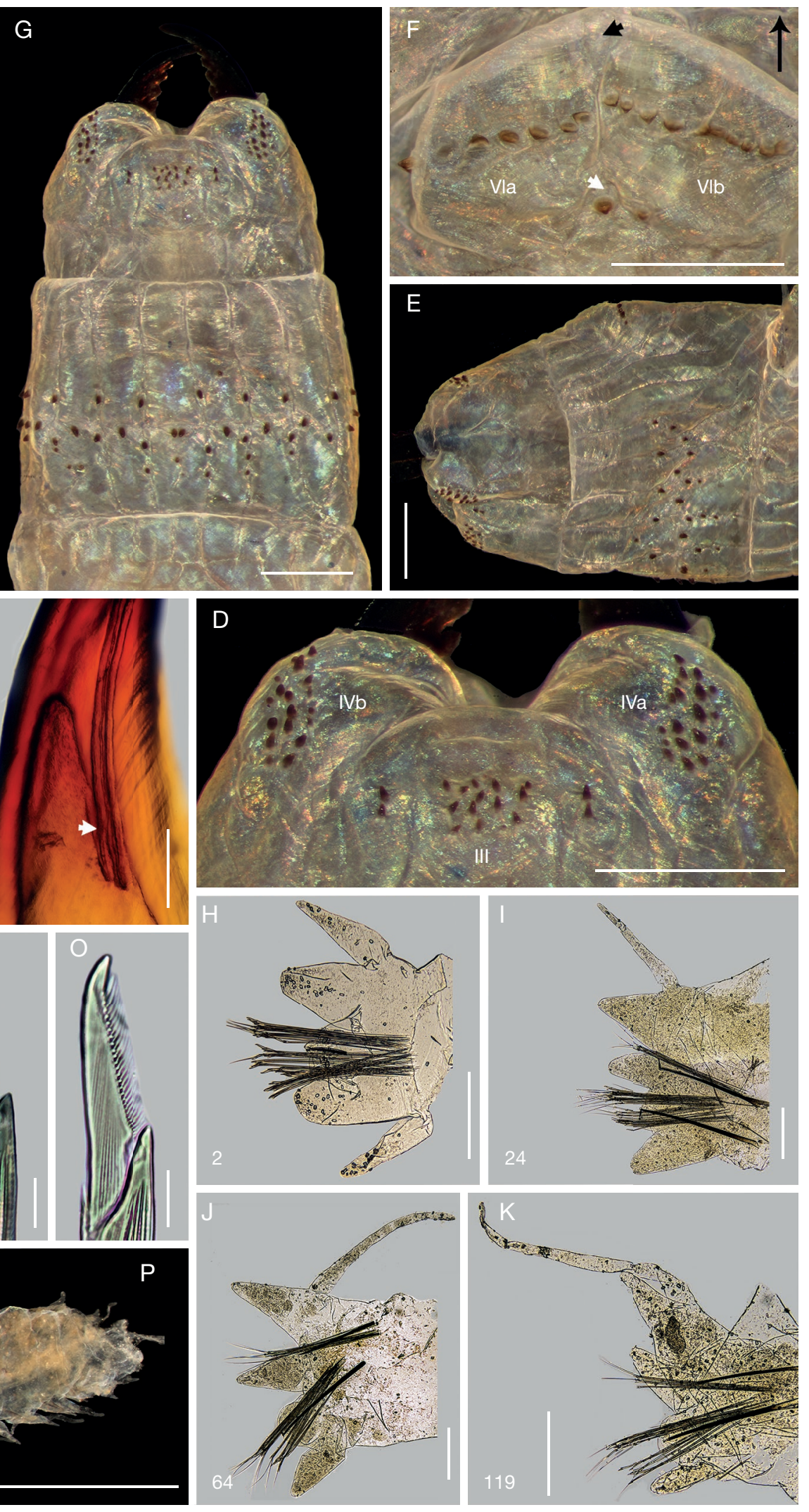

FIG. 2. - Perinereis nuntia (Savigny in Lamarck, 1818), topotypes (ZMB 4019-Q): A, F, I-P, from complete specimen; B-E, G, from incomplete specimen; A, anterior region, dorsal view; inset: left nuchal organ; B, right jaw, ventral (left) and dorsal (right) views; $\mathbf{C}$, same, close up of pulp cavity, ventral view (arrow points canal); D, maxillary ring of pharynx, ventral view; E, pharynx, lateral view; F, oral ring of pharynx, dorsal view; black arrowhead, distal portion of $x$-shaped pattern; white arrowhead, proximal portion of x-shaped pattern; black arrow, pointing anterior region; G, pharynx, ventral view; H-K, parapodia, anterior view (numbers refer the chaetiger); L, neuropodial homogomph spiniger, supracicular (chaet. 64); $\mathbf{M}$, heterogomph spiniger, subacicular (chaet. 24); N, heterogomph falciger, supracicular (chaet. 24); O, same, subacicular (chaet. 119); P, posterior region, dorsal view. Scale bars: A, 3 mm; B, D-G, P, 1 mm; C, 0.2 mm; H-K, 0.5 mm; L-O, 15 um. 


\section{REMARKS}

The species was briefly described but illustrated in detail based on at least two specimens (one with 118 segments) from the Gulf of Suez (Red Sea) (Savigny in Lamarck 1818; Savigny 1822), very likely from shallow waters of the city of Suez, as for others Savigny's polychaetes (e.g. Álvarez-Campos et al. 2015). Up to date, these materials have not been found within the polychaete collection at the MNHN, which currently preserve the types collected by Jules César Savigny during the Napoleonic campaign to Egypt. According to Solís-Weiss et al. (2004), some types remain "hidden" in this collection and the only possibility to find them is to inspect all the tubes in the different jars of the species in question; nevertheless, my focused search of the types of $P$. nuntia at the MNHN was not successful. Former zoologists who worked on this polychaete collection did not even mention the original P. nuntia material in their texts as they did for other Savigny's species (see Audouin \& Milne-Edwards 1833; de Quatrefages 1866; Gravier 1902). It is likely that the type material was missing ever since. I follow Wilson \& Glasby (1993) in regarding the specimens as lost.

The species was redescribed by Gravier (1902) using specimens from the southern Red Sea, separating it from other similar species, such as P. brevicirris (Grube, 1866) and P. quatrefagesi, based mainly on the length of dorsal and tentacular cirri, and on the number and arrangement of paragnaths on the pharynx. Fauvel (1911) recorded the species from Djibouti, the Persian Gulf, and the Reunion Island. Afterward, Fauvel (1919, 1921) introduced the six varieties within $P$. nuntia, regarding it as a single polymorphic species, widely distributed. The relevant features used by Fauvel to distinguish these varieties were the number of paragnaths on $\mathrm{AI}$ and $\mathrm{AV}$, the length of the tentacular and dorsal cirri, the shape of ligules, and the form of paragnaths on AVI.

In their revisionary effort of the $P$. nuntia species complex, Wilson \& Glasby (1993) mainly used the following features to differentiate the species: the number of paragnaths on the pharyngeal areas, the shape of paragnaths on AIV, AVI, and AVII-VIII, the number of rows on AVII-VIII, and the presence of heterogomph spinigers in anterior chaetigers. Regarding P. nuntia, Wilson \& Glasby (1993) redescribed the species using some specimens from the Red Sea collected by Felix Joussaume in 1894 (MNHN A108), but no details on a particular locality were given. According to several records of this and other Red Sea polychaetes collected by Joussaume in the same year (e.g. Gravier 1902, 1906; Hanley 1991; Wehe 2006), it is very likely that the material comes from the Perim Island, located at the Bab el-Mandeb Strait that connects the Red Sea and the Gulf of Aden. This place is about $2000 \mathrm{~km}$ of distance from the type locality, both placed in distant marine ecoregions (Spalding et al. 2007). Later, Glasby \& Hsieh (2006) expanded the previous redescription of $P$. nuntia, regarding it as a species with a wide distribution in the tropical Indo-Pacific, northern Australia, Taiwan, the Gulf of Aden, and the Red Sea; however, their specimens should be regarded as a distinct species (see below).
Yousefi et al. (2011) stated that their Iranian P. nuntia material fits well with the description of the species by Savigny (1822); however, some relevant differences are evident between them. The Iranian specimens have more paragnaths on AVI (13-20) than Savigny's (10-11; Savigny 1822: pl. 4, fig. 2.3), and the tentacular cirri are notoriously longer (extending backward to chaetigers 8-14) than those illustrated by Savigny (reaching about chaetiger 4). Indeed, the Iranian material has one of the highest number of paragnaths on AVI within the P. nuntia complex (see Wilson \& Glasby 1993; Glasby \& Hsieh 2006; Park \& Kim 2007). Furthermore, Yousefi et al. (2011) noticed some differences between their material and the redescription of P. nuntia (Wilson \& Glasby 1993). For example, the Iranian specimens had more paragnaths on the oral ring and more transverse rows on AVII-VIII. Likewise, they also recognized some distinctions in accordance to Glasby \& Hsieh's P. nuntia material, such as the presence of heterogomph spinigers throughout body (absent in anterior neuropodia sensu Glasby \& Hsieh 2006) and the posterodorsal tentacular cirri reaching chaetigers 8-14 (6-8 in Glasby $\&$ Hsieh's specimens).

The $P$. nuntia specimens herein examined from the Red Sea, which once belonged to A. E. Grube's collection and are now deposited at the ZMB, match in accuracy with the Savigny's original description and illustrations of $P$. nuntia. For instance, the sub-pentagonal prostomium with narrowing end; the $\chi$-shaped pattern of AVI-V-VI; the triangular arrangement of cones on AV; the number of paragnaths on AI (1-3 in Grube's vs 1 in Savigny's), AII (9-10 in Grube's vs 6-10 in Savigny's), AIII (11-19 in Grube's vs 14 in Savigny's), AIV (14-19 in Grube's vs 14 in Savigny's), AV (2-4 in Grube's vs 3 in Savigny's), and AVI (8-10 in Grube's vs 10-11 in Savigny's); the 4-5 transverse rows of paragnaths on AVIIVIII (2-3 most proximal rows with smaller cones). Also, the slender dorsal cirri which show similar size variations, they are much longer than the dorsal ligule in posterior parapodia (3-4 times in Grube's vs 4-5 times in Savigny's); the absence of merged paragnaths on AIV; and even the unusually short tentacular cirri. These are some of the most relevant features to distinguish $P$. nuntia sensu stricto from the species within the complex, as well as the two canals in the jaws, and the presence of heterogomph spinigers in all the neuropodial subacicular fascicles. Therefore, these specimens are also different from those previously referred as $P$. nuntia by Gravier (1902) and Wilson \& Glasby (1993) from the southern Red Sea, Glasby \& Hsieh (2006) from the Indo-Pacific, and Yousefi et al. (2011) from the Gulf of Oman. The several records of P. nuntia in several regions need to be thoroughly assessed.

On the other hand, collecting data are scarce in the catalog and labels for the Grube's specimens of P. nuntia. Most of the material from the Red Sea revised by Grube was collected by Christian Gottfried Ehrenberg and Georg Ritter von Frauenfeld, and many of them resulted in previously undescribed taxa (Grube 1868, 1869; see also Wiktor 1980 and Hartwich 1993). The marine invertebrates collected by Ehrenberg and von Frauenfeld were mainly obtained from the sediments or coral reefs of the Northern and Central Red Sea (Ehrenberg 
1828; von Frauenfeld 1856). However, despite the similar morphology to those specimens originally described from the Northern Red Sea (Savigny in Lamarck 1818), there is no certainty of the precise Red Sea location nor the collector. Therefore, some of the required conditions to establish a neotype could not be met (ICZN 1999, Art. 75.3).

Perinereis latipalpa (Schmarda, 1861), reinst., n. comb. (Figs 1A-C; 3A-I; 4A-L; 5A-L; 6A-O; 7A-E)

Nereis (Nereis) latipalpa Schmarda, 1861: 104-105, textfig. A, B, K, a, b, pl. 31, fig. 244 .

Neanthes latipalpa - Kinberg 1865: 171. — von Marenzeller 1888: 6-7, fig. 2. n. syn.

Neanthes latipalpa typica - Willey 1904: 260-261, pl. 13, fig. 9, pl. 14, figs 1, 2, 2a, b. n. syn.

Perinereis nuntia vallata - Day 1967: 334, fig. 14.12.p-s (material from South Africa, partim, non Grube \& Kröyer in Grube 1858).

Perinereis namibia Wilson \& Glasby, 1993: 265-266, fig. 10a-k. n. syn.

TYPE MATERIAL. - 9 specimens of Nereis (Nereis) latipalpa (originally labelled as "cotypen") in three different lots. Herein, 1 designated as lectotype NMHW 769a and 8 as paralectotypes NMHW 769b, 770, 771. Collected by L. Schmarda, Table Bay, Cape Town (originally as "Tafelbai", "Cap."), South Africa, mud, under stones. Older label and catalog number attached on the outer surface of each jars which originally belonged to the "Zoologisch-vergleichend-anatomische Sammlung, Universität Wien" (Fig. 3A). Recent labels inside the jars with the NMHW imprint (as "Coll. Musei Vindobonensis, Evertebrata varia") and handwritten (Fig. 3A) (see remarks for additional information). - Holotype of Neanthes latipalpa Kinberg, 1865 SMNH 37900, collected by Eugenie Expedition 1851-1853, sta. 1620-28, Green Point Lighthouse, Cape Town, South Africa, 9 Apr. 1854; jar with one original and two recent labels. One permanent slide of holotype's left parapodium 27th SMNH 37900, housed at the NHMUK (Fig. 5L), apparently loaned to NHMUK for Arthur Willey. - Sixteen syntypes of Neanthes latipalpa typica Willey, 1904 NHMUK 1911.2.1.23-26, collected by W.F. Purcell, Green Point, Table Bay, Cape Town, South Africa, Nov. 1896. One slide of a syntype NHMUK 1911.2.1.23-26a; Fig. 6N, right parapodia 8, 33 and 73. One slide of a syntype NHMUK 1911.2.1.23-26b; Fig. 6O, small specimen, right parapodium 28.

Additional Material. - Seven specimens of Perinereis namibia Wilson \& Glasby, 1993 (ZMB 4109b), collected by L. Schultze, Lüderitz Bay, Namibia, Jul. 1903, identified by R. Wilson and C. Glasby. - One specimen of Perinereis vallata (Grube \& Kröyer in Grube, 1858) (ZMB 3666), collected by L. Plate, Puerto Montt, Los Lagos, Chile, identified by A.E. Grube and E. Ehlers. -One specimen of Perinereis akuna Wilson \& Glasby, 1993 (LACM-AHF Poly 10199), collected by S. J. Edmonds, Venus Bay inlet, Eyre Peninsula, South Australia, 33 $13^{\prime} 00^{\prime \prime}$ S, $134^{\circ} 40^{\prime} 00^{\prime}$ E, associated with Modiolus areolatus (Gould) clusters, no date, identified by T. Villalobos.

DiAGNOSIS. - Specimens with antennae separated, nuchal organs subequal to posterior eyes, postero-dorsal tentacular cirri reaching chaetigers 3-6. Jaws with 5-6 canals. Maxillary ring: $A I=1-2$; $\mathrm{AII}=2-10 ; \mathrm{AIII}=8-20,1-2$ lateral cones; $\mathrm{AIV}=14-28$, merged par agnaths absent. Oral ring: AVI-V-VI pattern, $\lambda$-shaped; $A V=0-2$, paragnaths slightly behind AVI; AVI $=9-12$, arc long, oblique, bars short, even; AVII-VIII = 48-66, 2-3 transverse rows, proximal with large cones. Gap between AVI and AVII-VIII narrow. Dorsal cirri 1.5-2 times longer than dorsal ligule, inserted posteriorly on three- quarters of it. Dorsal ligule barely uneven throughout body, subequal to median ligule; distal lobe bluntly conical posteriorly. Ventral cirri cirriform. Homogomph spinigers with proximal teeth notoriously thickened, separated; absent in subacicular neurochaeta. Heterogomph spinigers with proximal teeth barely thickened, evenly spaced; present throughout. Heterogomph falcigers with medium blades.

VARIATIONS. $-\mathrm{LT}=48-145 \mathrm{~mm}, \mathrm{~L} 15=8-24 \mathrm{~mm}, \mathrm{~W} 15=1.7-$ $5.5 \mathrm{~mm}, 89-143$ chaetigers. Antero-dorsal tentacular cirri reaching chaetiger 1-2. Postero-dorsal reaching chaetiger 3-6. Jaws with 4-8 denticles, 5-6 canals. Paragnaths: $I=1-2, I I=2-10$, III $=8-20$, lateral cones $1-2, I V=14-28$, none merged paragnaths, $V=0-2, V I=9-12$, VII-VIII $=48-66$, arranged in 2-3 transverse rows. Dorsal ligule expanding from parapodia 26-38. Notoacicular process developed in parapodia 5 to 14-22. Superior lobe developed in first 53-57 parapodia, projecting beyond end of neuracicular ligule in first 22-25 parapodia. Anal cirri as long as last 4-9 chaetigers. Falcigers with serrated region $0.43-0.52$ total blade length.

HABITAT. — Mud beneath stones (Schmarda 1861), among rocks (Willey 1904).

Type Locality. — Table Bay, Cape of Good Hope, South Africa.

Distribution. - Lüderitz Bay, Namibia and Table Bay, Cape Town, South Africa.

\section{DESCRIPTION (LECTOTYPE AND TWO PARALECTOTYPES) \\ Lectotype, MPW 769a, atoke, complete}

Measurements. TL $=127 \mathrm{~mm}, \mathrm{~L} 15=20.5 \mathrm{~mm}, \mathrm{~W} 15=5 \mathrm{~mm}$, with 109 chaetigers. Paralectotypes atokes, longer female, complete, smaller lacking posterior region, $\mathrm{TL}=95-137 \mathrm{~mm}$, L15 = 19-23.7 mm, W15=4.5-4.6 mm, with 49-131 chaetigers.

Pigmentation. Brown, most intense anteriorly. Blackish glandular patches in ligules, cirrophore of ventral cirri and ventral ends of segments, most intense posteriorly (Fig. 3C); same glandulation running transversally on dorsum of posterior segments (Fig. 3C).

Head. Prostomium sub-pentagonal with broad anterior end (Fig. 3B), as long as wide; anterolateral sides 1.5 times wider than antennal diameter. Palpophores oval (Fig. 3B), massive, slightly longer than wide, equaling entire length of prostomium; one deep wrinkle placed obliquely in one-half of palpophore. Antennae separated, gap three-quarters of antennal diameter (Fig. 3B); conical, slender, extending backward to one-third of prostomium. Eyes in sub-trapezoidal arrangement, blackish, anterior and posterior pairs well separated (twice size of posterior; Fig. 3B); lens barely visible, grayish. Anterior pair of eyes rounded, nearly subequal to antennal diameter; lens oval, located anterolaterally, touching margin of eye, covering $20 \%$. Posterior pair of eyes rounded, similar-sized to anterior pair; lens rounded, located posterolaterally, not touching margin, covering $70 \%$. Nuchal organs deeply embedded, slightly convex, subequal to posterior eyes (Fig. 3B).

Apodous anterior segment $\&$ tentacular cirri. Apodous anterior segment 4 times wider than long, 1.4 (1.4-1.5) times longer than chaetiger 1 . Tentacular cirri pattern: Postero-dorsal cirri 1.5 times longer than antero-dorsal ones; anterior-ventral cirri slightly longer than postero-ventral one. Antero-dorsal 

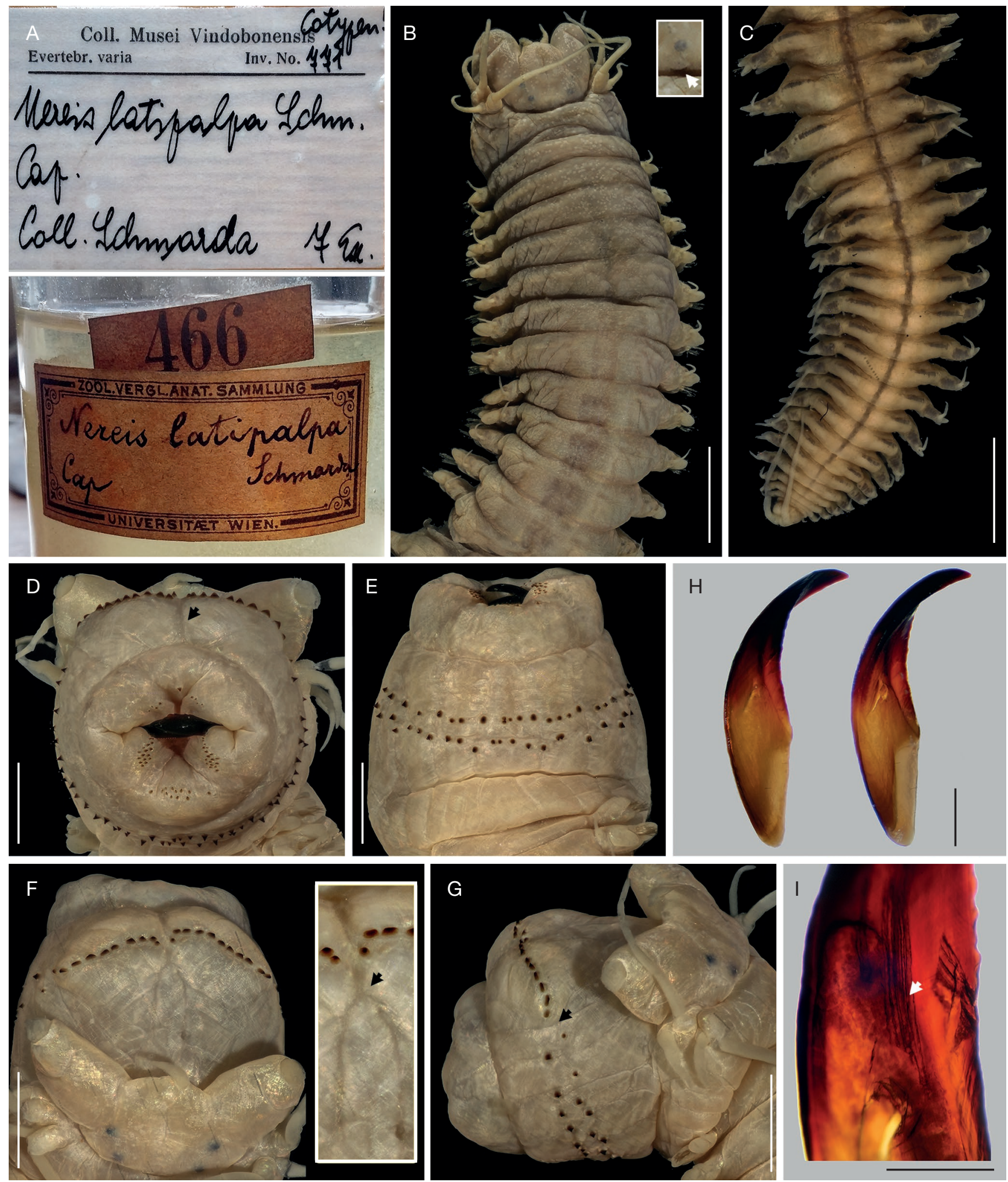

FIG. 3. - Perinereis latipalpa (Schmarda, 1861) n. comb: A, recent (above) and older (below) labels of the jars containing paralectotype materials at the Natural History Museum, Vienna (NMHW 771); B, C, lectotype (NMHW 769a); D-I, Paralectotype (NMHW 771); B, anterior region, dorsal view; C, posterior region, dorsal view; D, pharynx, anterior view (arrow points distal portion of $\lambda$-shaped pattern); $\mathbf{E}$, same, ventral view; $\mathbf{F}$, same, dorsal view; inset: entire $\lambda$-shaped pattern (arrow points proximal overlap of areas V and VI); G, same, lateral view (arrow points narrow gap); H, left jaw, dorsal (left) and ventral (right) views; I, same, zoom-in, ventral view (arrow: canals). Scale bars: B, C, $3 \mathrm{~mm}$; D-G, $2 \mathrm{~mm} ; \mathrm{H}, 1 \mathrm{~mm} ; \mathrm{I}, 0.5 \mathrm{~mm}$. 
cirri reaching chaetiger 1 (1-2); antero-ventral slightly smaller than palpophore. Postero-dorsal reaching chaetiger 3 (2-5); postero-ventral extending over prostomium to reach one-third of it. Dorsal cirrophores wrinkled, cylindrical; postero-dorsal cirrophores longest, 2.5 times length of postero-ventral ringshaped ones.

Pharynx. Not everted, previously dissected (based on lectotype, figures referring to a paralectotype with everted pharynx). Only one jaw available, blackish in distal quarter, then brownish; 7 (6-8) denticles, poorly developed, inner margin of fang flattened, equaling next 4 denticles; pulp cavity two-fifths (two-fifths to three-fifths) length of jaw (Fig. 3H), distal apex leveling third basal denticle; 5 (5-6) longitudinal canals emerging from pulp cavity (Fig. 3I). Maxillary ring (Fig. 3D): paragnaths conical, none worn, brownish amber colored, much smaller than those on oral ring. $\mathrm{AI}=1(1-2)$, longer than those on AII. AIIa $=4$ (4-5), AIIb = 5 (4-9), oblique irregular patch, two irregular rows. AIII = 9 (9-12), oval patch, two slightly regular transverse rows, one cone laterally isolated in each side. AIVa $=18$ (19-22), AIVb = 23 (19-27), lemniscate-shaped patch, maxillary portion smaller than proximal one, outer cones smallest; merged paragnaths absent. Oral ring (Fig. 3E-G): AVI-V-VI pattern, $\lambda$-shaped; AVI overlapping proximally AV further behind arc of paragnaths (Fig. 3F). Paragnaths conical and shield-shaped bars, reddish amber colored. AV = $1(1-2)$, aligned to paragnaths of AVI. AVIa =9 (9-10), AVIb = $11(9-10)$, arc of paragnaths long, slightly oblique, shield-shaped bars; bars short, tip barely worn, similar in length; ridges prominent, broad, slightly wider than palpophore. AVII-VIII = 53 (4966), conical paragnaths, bigger ones arranged in longitudinal wrinkles of ring (Fig. 3E); single band of two main rows, not increasing in number dorsoventrally, distal row slightly more regular than proximal one. Gap between AVI and AVII-VIII narrow, as wide as palpostyle (Fig. 3G).

Notopodia. Dorsal cirrus slightly longer than dorsal ligule in first parapodia, subequal to ligule or slightly longer in anterior and median parapodia, 1.5-2 times longer in posterior ones; cirri longer than length of proximal lobe of dorsal ligule in anterior parapodia (Fig. 4A, B), subequal to it from median ones (Fig. 4C-F); cirrus inserted on one-third in anterior parapodia (Fig. 4A, B), one-half in median (Fig. 4C, D), three-quarters in posterior ones (Fig. 4E, F). Dorsal ligule somewhat uneven throughout body, becoming wider from parapodia 35 (28-37), barely expanded from about parapodia 85 (Fig. 4E, F); ligule 2.5 (2.3-2.5) times width of median ligule in posterior parapodia (Fig. 4E, F). Distal lobe of dorsal ligule bluntly conical, longer than proximal one in anterior parapodia, two-thirds or three-fifths length of proximal in median, one-third or two-fifths length in posterior ones (Fig. 4E, F). Dorsal ligule subequal to median ligule in anterior parapodia, slightly shorter in median (Fig. 4C, D), slightly longer in posterior ones (Fig. 4E, F). Two main glandular patches in dorsal ligule, central and proximal (Fig. 4F); oval, similar-sized in anterior parapodia (covering 25-30\% of total ligule area; Fig. 4B); proximal patch 1.5 times bigger than central one in median parapodia (covering $40-50 \%$ of total ligule area; Fig. 4D) and twice bigger in posterior ones (covering 60-70\% of total ligule area; Fig. 4F). Notoacicular process developed from parapodia 5 to 21 (14-22), digitiform, short.

Neuropodia. Neuracicular ligule subequal to ventral ligule or slightly longer throughout body; 1.5 times wider than ventral ligule in anterior parapodia, twice wider from median ones. Superior lobe digitiform (Fig. 4C), shorter than inferior lobe and projecting beyond end of neuracicular ligule in first 25 (22-24), reduced from parapodia 57 (54-58). Inferior lobe rounded (Fig. 4A, B), narrowing progressively from parapodia 28 (25-27). Ventral ligule digitiform, shorter than median ligule throughout body; two-thirds length of ligule in anterior parapodia, one-half length from median ones. Ventral cirri cirriform, smaller than ventral ligule throughout body, onehalf length of ligule, except in first 5 parapodia, three-quarters or nearly subequal to ligule.

Chaetae. Notochaetae with homogomph spinigers, blade with few first proximal teeth thick, notoriously separated (Fig. 4G, $\mathrm{H})$. Neurochaetal supracicular fascicle with homogomph spinigers and heterogomph falcigers, both present throughout; spinigers as notopodial ones, more numerous than falcigers in fascicle; falcigers with blade of medium length $(b / a=1.27$ 1.57 times), serrated region $0.50-0.52$ of total blade length (Fig. 4J). Neurochaetal subacicular fascicle with heterogomph spinigers and heterogomph falcigers, both present throughout; spinigers with proximal teeth barely thickened, evenly spaced (Fig. 4I), less numerous than falcigers in fascicle; falcigers with blade of medium length $(b / a=1.61-1.79$ times $)$, serrated region $0.49-0.51$ of total blade length (Fig. $4 \mathrm{~K}, \mathrm{~L}$ ).

Pygidium. With slender anal cirri (Fig. 3C), as long as last 9 (7) parapodia, cirrophores well developed, broad.

Holotype of Neanthes latipalpa Kinberg (Fig. 5A-L)

Body. Atoke, SMNH 37900, complete, TL $=50 \mathrm{~mm}, \mathrm{~L} 15=$ $10.8 \mathrm{~mm}, \mathrm{~W} 15=2.4 \mathrm{~mm}$, with 89 chaetigers. Body pigmentation absent, probably faded. Blackish glandular patches in ligules, cirrophore of ventral cirri and ventral ends of segments, most intense posteriorly.

Head. Prostomium sub-pentagonal, broad anterior end; barely longer than wide (Fig. 5A). Palpophores oval, massive, as long as wide (Fig. 5A, C), nearly equaling entire length of prostomium. Antennae separated (Fig. 5A), conical, slender, extending backward to one-quarter of prostomium. Eyes in sub-trapezoidal arrangement, blackish (Fig. 5A, C); anterior pair barely reniform due to lens, subequeal to antennal diameter, lens anterolateral, covering 30\%; posterior pair rounded, slightly shorter than anterior, lens posterolateral, covering $60 \%$.

Apodous anterior segment $\&$ tentacular cirri. Apodous anterior segment 3 times wider than long, 1.3 times longer than chaetiger 1. Antero-dorsal tentacular cirri reaching chaetiger 1 , anteroventral one smaller than palpophore. Postero-dorsal reaching 

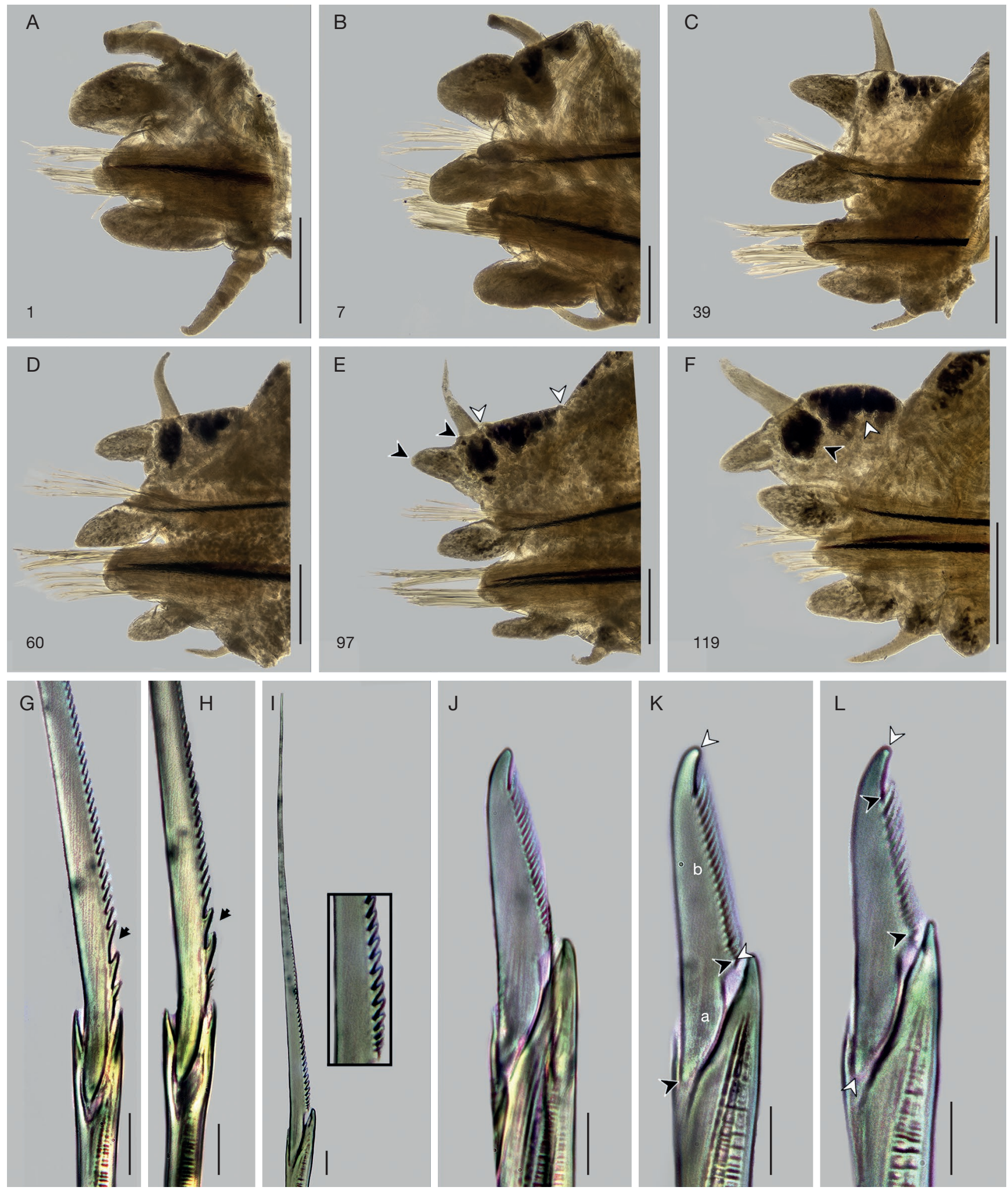

FIG. 4. - Perinereis latipalpa (Schmarda, 1861) n. comb. lectotype (NMHW 769a): A-F, parapodia, anterior view (numbers refer the chaetiger); A, B, with bent dorsal cirri; E, black arrowheads, points used for measuring entire length of distal lobe of dorsal ligule; white, same but for proximal lobe; $\mathbf{F}$, with incomplete dorsal cirri; black arrowheads, central glandular patch; white, proximal patch; $\mathbf{G}, \mathbf{H}$, approach of notopodial homogomph spinigers (chaet. 39 and 60 , respectively) (arrows point thick, separated teeth); I, Heterogomph spiniger (chaet. 60); inset: proximal teeth; J, neuropodial heterogomph falciger, supracicular (chaet. 60); K, same, subacicular (chaet. 60); black arrowheads, points used for measuring length of blade of the proximal end (a); white, same but for distal end (b); L, same, subacicular (chaet. 119), black arrowheads, points used for measuring length of the serrated region; white, same but for entire length of blade. Scale bars: A-F, $0.5 \mathrm{~mm}$; G-L, $15 \mu \mathrm{m}$. 
chaetiger 2 but incomplete, postero-ventral one extending over prostomium to reach one-third of it. Postero-dorsal cirrophores longest, 2 times length of postero-ventral ring-shaped ones.

Pharynx. Everted, damaged (Fig. 5A-C), paragnath areas still recognizable, jaws not present. Maxillary ring (Fig. 5B): paragnaths conical, small, brownish amber. $\mathrm{AI}=2$, in longitudinal line. $\mathrm{AIIa}=4$, $\mathrm{AIIb}=4$, oblique row. $\mathrm{AIII}=8$, rectangular patch, two slightly regular rows. AIVa $=14, \mathrm{AIVb}=16$, spoonshaped patch, merged paragnaths absent. Oral ring (Fig. 5BD): AVI-V-VI pattern, $\lambda$-shaped; AVI overlapping proximally AV further behind arc of paragnaths (Fig. 5B). Paragnaths conical, except shield-shaped bars on AVI, brownish amber. $\mathrm{AV}=1$, aligned to paragnaths of AVI. $\mathrm{AVIa}=11, \mathrm{AVIb}=11$, arc of paragnaths long, oblique, bars short, similar in length, tip barely worn. AVII-VIII = 56, single band of two main rows, irregular. Gap between AVI and AVII-VIII narrow (Fig. 5C).

Notopodia. Dorsal cirri slightly longer than dorsal ligule in first parapodia, subequal to ligule or slightly longer in anterior and median parapodia (Fig. 5F-H), 1.5-2 times longer in posterior ones (Fig. 5I); cirri inserted on one-third in anterior parapodia, one-half in median, three-quarters in posterior ones. Dorsal ligule becoming wider from parapodia 27, barely expanded from about parapodia 65 (Fig. 5I); subequal to median ligule in anterior and median parapodia (Fig. 5F$\mathrm{H}$ ), longer in posterior ones (Fig. 5I). Two main glandular patches in dorsal ligule, central and proximal, most intense in posterior parapodia. Notoacicular process developed from parapodia 5 to 14 , digitiform, short.

Neuropodia. Neuracicular ligule subequal to ventral ligule or slightly longer. Superior lobe digitiform (Fig. 5F, G), projecting beyond end of neuracicular ligule in first 22 parapodia, reduced from parapodia 56. Ventral cirri smaller than ventral ligule.

Chaetae. Homogomph spinigers with blade bearing few first proximal teeth thickened and notoriously separated (Fig. 5J). Heterogomph spinigers present in all chaetigers, blade with proximal teeth barely thickened, evenly spaced. Falcigers in both fascicles with serrated region 0.49-0.51 total blade length (Fig. 5K).

Pygidium. With slightly thickened anal cirri (Fig. 5E), apparently incomplete, as long as last 4 parapodia; cirrophores well developed.

\section{Syntype of Neanthes latipalpa typica (Fig. 6A-O)}

Body. Atoke, NHMUK 1911.2.1.23-26, complete, $\mathrm{TL}=48 \mathrm{~mm}$, $\mathrm{L} 15=8.3 \mathrm{~mm}, \mathrm{~W} 15=1.7 \mathrm{~mm}$, with 93 chaetigers. Body pigmentation on dorsal surface, faint, pale brown, most intense anteriorly. Brownish glandular patches in ligules, cirrophore of ventral cirri and ventral ends of segments.

Head. Prostomium sub-pentagonal, broad anterior end; barely longer than wide (Fig. 6A). Palpophores oval, massive, as long as wide (Fig. 6B), equaling entire length of prostomium. Antennae separated (Fig. 6A), conical, slender, extending backward to one-quarter of prostomium. Eyes in sub-trapezoidal arrangement, blackish (Fig. 6A); anterior pair barely reniform due to lens, slightly wider than antennal diameter, lens anterolateral, covering $25 \%$; posterior pair rounded, slightly shorter than anterior, lens posterolateral, covering $40 \%$.

Apodous anterior segment $\&$ tentacular cirri. Apodous anterior segment 3.4 times wider than long, 1.4 times longer than chaetiger 1 . Antero-dorsal tentacular cirri reaching chaetiger 2 , antero-ventral one smaller than palpophore. Postero-dorsal reaching chaetiger 5 , postero-ventral one extending over prostomium to reach one-half of it. Postero-dorsal cirrophores longest, 2 times length of postero-ventral ring-shaped ones.

Pharynx. Not everted. Jaws with 6 denticles, barely prolonged; pulp cavity two-fifths length of jaw, oblique distal apex, five longitudinal canals (Fig. 6C). Maxillary ring (Fig. 6D): paragnaths conical, small, dusky brown. $\mathrm{AI}=1$, longer than cones on AII. $\mathrm{AIIa}=9, \mathrm{AIIb}=10$, irregular oblique patch. $\mathrm{AIII}=12$, oval patch in three rows, one isolated cone. $\mathrm{AIVa}=21, \mathrm{AIVb}=21$, spoon-shaped patch, merged paragnaths absent. Oral ring (Fig. 6E): AVI-V-VI pattern, $\lambda$-shaped; AVI overlapping proximally AV further behind arc of paragnaths. Paragnaths conical, except shield-shaped bars on AVI, dusky brown. $\mathrm{AV}=1$, aligned to paragnaths of $\mathrm{AVI} . \mathrm{AVIa}=10, \mathrm{AVIb}=10$, arc of paragnaths long, oblique (Fig. 6E), bars short, similar length, tip barely worn. AVII-VIII $=52$, single band of two main rows, irregular. Gap between AVI and AVII-VIII narrow.

Notopodia. Dorsal cirri longer than dorsal ligule in first parapodia, subequal to ligule or slightly longer in anterior and median parapodia (Fig. 6G-I), 1.5-2 times longer in posterior ones (Fig. 6J); cirri inserted on one-third in anterior parapodia, one-half in median, three-quarters in posterior ones. Dorsal ligule becoming wider from parapodia 29, barely expanded from about parapodia 63 (Fig. 6J); subequal to median ligule in anterior and median parapodia (Fig. 6G-I), longer in posterior ones (Fig. 6J). Two main glandular patches in dorsal ligule, central and proximal, most intense in posterior parapodia. Notoacicular process developed from parapodia 5 to 18 , digitiform, short.

Neuropodia. Neuracicular ligule slightly longer than ventral ligule. Superior lobe digitiform (Fig. 6G, H), projecting beyond end of neuracicular ligule in first 24 parapodia, reduced from parapodia 54. Ventral cirri smaller than ventral ligule, except in first anterior parapodia, subequal to it.

Chaetae. Homogomph spinigers with blade bearing few first proximal teeth thickened and notoriously separated (Fig. 6K). Heterogomph spinigers present in all chaetigers, blade with proximal teeth barely thickened, evenly spaced. Falcigers in both fascicles with serrated region 0.47-0.49 total blade length (Fig. 6L, M).

Pygidium. With slightly thickened anal cirri (Fig. 6F), as long as last 6 parapodia, cirrophores well developed. 

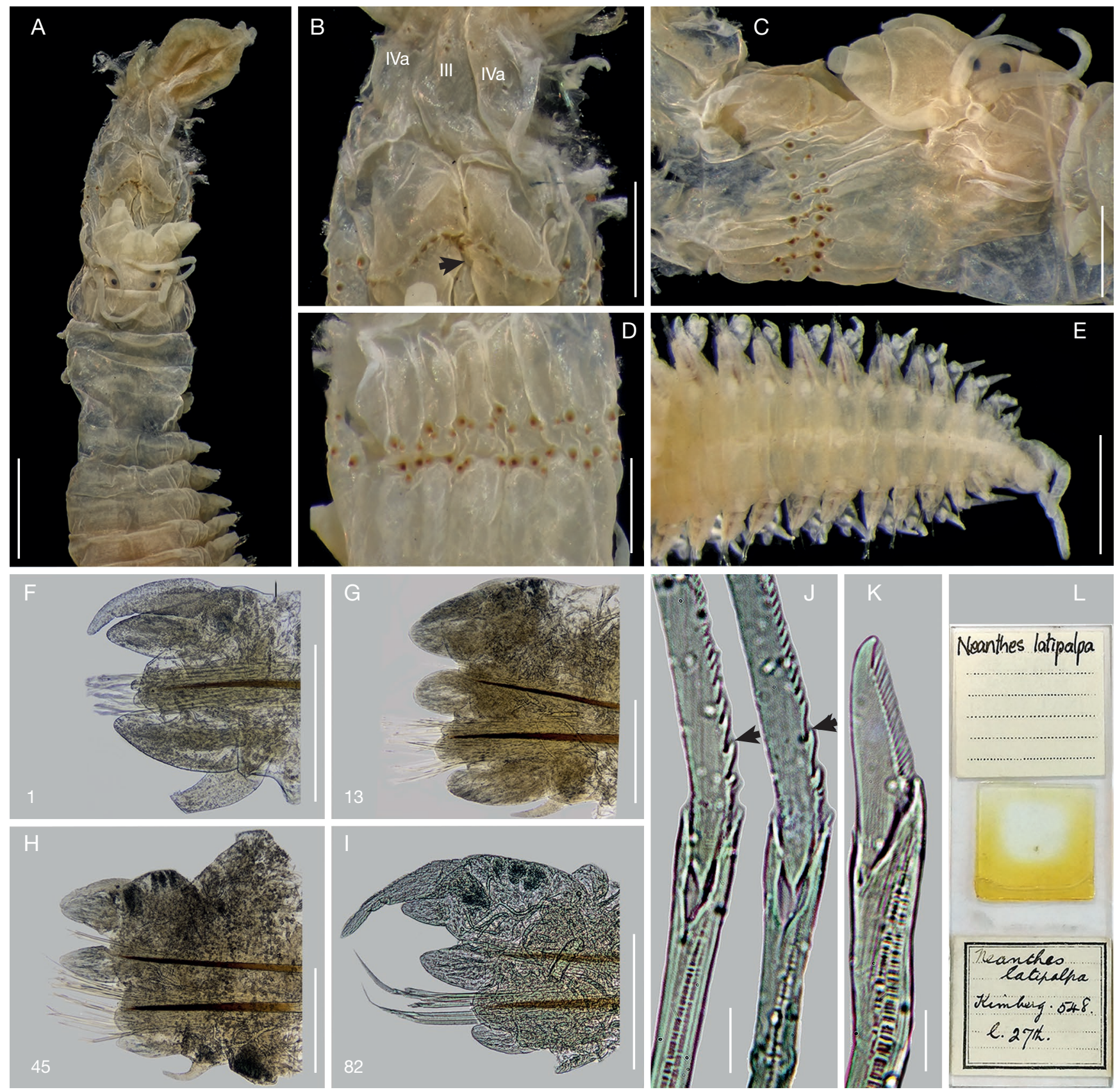

FIG. 5. - Perinereis latipalpa (Schmarda, 1861) n. comb., holotype of Neanthes latipalpa Kinberg, 1865 n. syn. (SMNH 37900$)$ : A, anterior region, dorsal view; B, pharynx, dorsal view (arrow points proximal overlap of areas $\mathrm{V}$ and $\mathrm{VI}$ ); C, oral ring of pharynx, lateral view; $\mathbf{D}$, same, ventral view; E, posterior region, ventral view; F-I, parapodia, anterior view (numbers refer the chaetiger); J, approach of notopodial homogomph spinigers (chaet. 45) (arrows point thicker, separated teeth); K, neuropodial heterogomph falciger, subacicular (chaet. 45); L, permanent microscope slide, mounted 27th parapodia (SMNH 37900 , housed at the NHMUK). Scale bars: A, 2 mm; B-E, $1 \mathrm{~mm}$; F-H, $0.5 \mathrm{~mm}$; I, $0.3 \mathrm{~mm}$; J, K, $15 \mu \mathrm{m}$.

Topotype of Perinereis namibia (Fig. 7A-E)

Body \& head. Atoke, ZMB 4109b, complete. Prostomium sub-pentagonal, broad anterior end. Palpophores oval, massive, as long as wide. Antennae separated, conical, slender, extending backward to one-third of prostomium. Eyes in subtrapezoidal arrangement; anterior pair rounded, subequal to antennal diameter, lens anterolateral, covering $20 \%$; posterior pair rounded, slightly shorter than anterior pair, lens posterolateral, covering $30 \%$. Apodous anterior segment 3 times wider than long, 1.3 times longer than chaetiger 1 .
Pharynx. Everted. Jaws with 6 denticles, barely prolonged. Maxillary ring (Fig. 7A): paragnaths conical, small, dusky brown. $\mathrm{AI}=1$, barely longer than cones on AII. AIIa $=4$, $\mathrm{AIIb}=5$, oblique row. AIII $=12$, oval patch in three irregular rows, one isolated cone. $\mathrm{AIVa}=22, \mathrm{AIVb}=22$, lemniscateshaped patch, merged paragnaths absent. Oral ring (Fig. 7B, C): AVI-V-VI pattern, $\lambda$-shaped; AVI overlapping proximally AV further behind arc of paragnaths (Fig. 7B). Paragnaths conical, except shield-shaped bars on AVI, dusky brown. $\mathrm{AV}=1$, aligned to paragnaths of AVI. AVIa $=10, \mathrm{AVIb}=9$, 

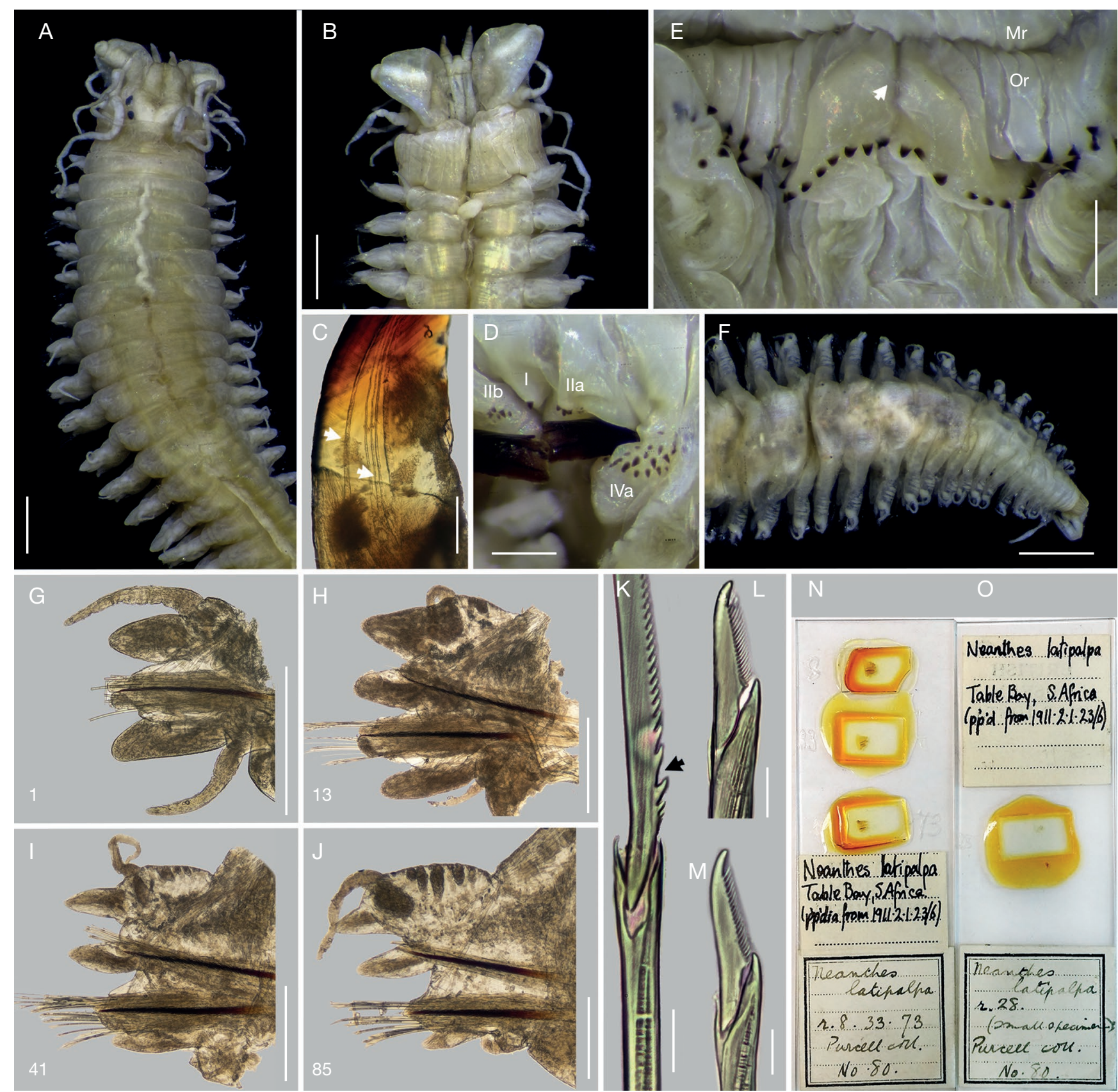

O

FIG. 6. - Perinereis latipalpa (Schmarda, 1861) n. comb., syntypes of Neanthes latipalpa typica Willey, 1904 n. syn. (NHMUK 1911.2.1.23-26); A, anterior region, dorsal view; B, same, ventral view; C, right jaw, ventral view (arrows point canals); D, maxillary ring of pharynx, ventral view; E, oral ring of pharynx, ventral view (arrow points distal portion of $\lambda$-shaped pattern); $\mathbf{F}$, posterior region, dorsal view; G-J, parapodia, anterior view (numbers refer the chaetiger); K, approach of notopodial homogomph spiniger (chaet. 41) (arrow points thicker, separated teeth); L, neuropodial heterogomph falciger, supracicular (chaet. 41); $\mathbf{M}$, same, subacicular (chaet. 41); N, permanent microscope slide with mounted 8th, 33rd and 73rd parapodia (NHMUK 1911.2.1.23-26a); O, same, 28th parapodia (NHMUK 1911.2.1.23-26b). Scale bars: A, B, F, 1 mm; C, 0.2 mm; D, E, G-J, 0.5 mm; K-M, 15 um.

arc of paragnaths long, oblique (Fig. 7B), bars short, similar in length, tip barely worn. AVII-VIII = 54, single band of two main rows, irregular (Fig. 7C). Gap between AVI and AVII-VIII narrow.

Notopodia. Dorsal ligule becoming barely expanded from parapodia 32; subequal to median ligule in anterior parapodia, barely shorter in median, slightly longer in posterior ones (Fig. 7D). Two main glandular patches in dorsal ligule, central and proximal, most intense in posterior parapodia (Fig. 7D). Notoacicular process developed from parapodia 5 to 23 , digitiform, short.

Neuropodia. Neuracicular ligule slightly longer than ventral ligule (Fig. 7D). Superior lobe digitiform, projecting beyond end of neuracicular ligule in first 26 parapodia, reduced from parapodia 56. Ventral cirri smaller than ventral ligule. 

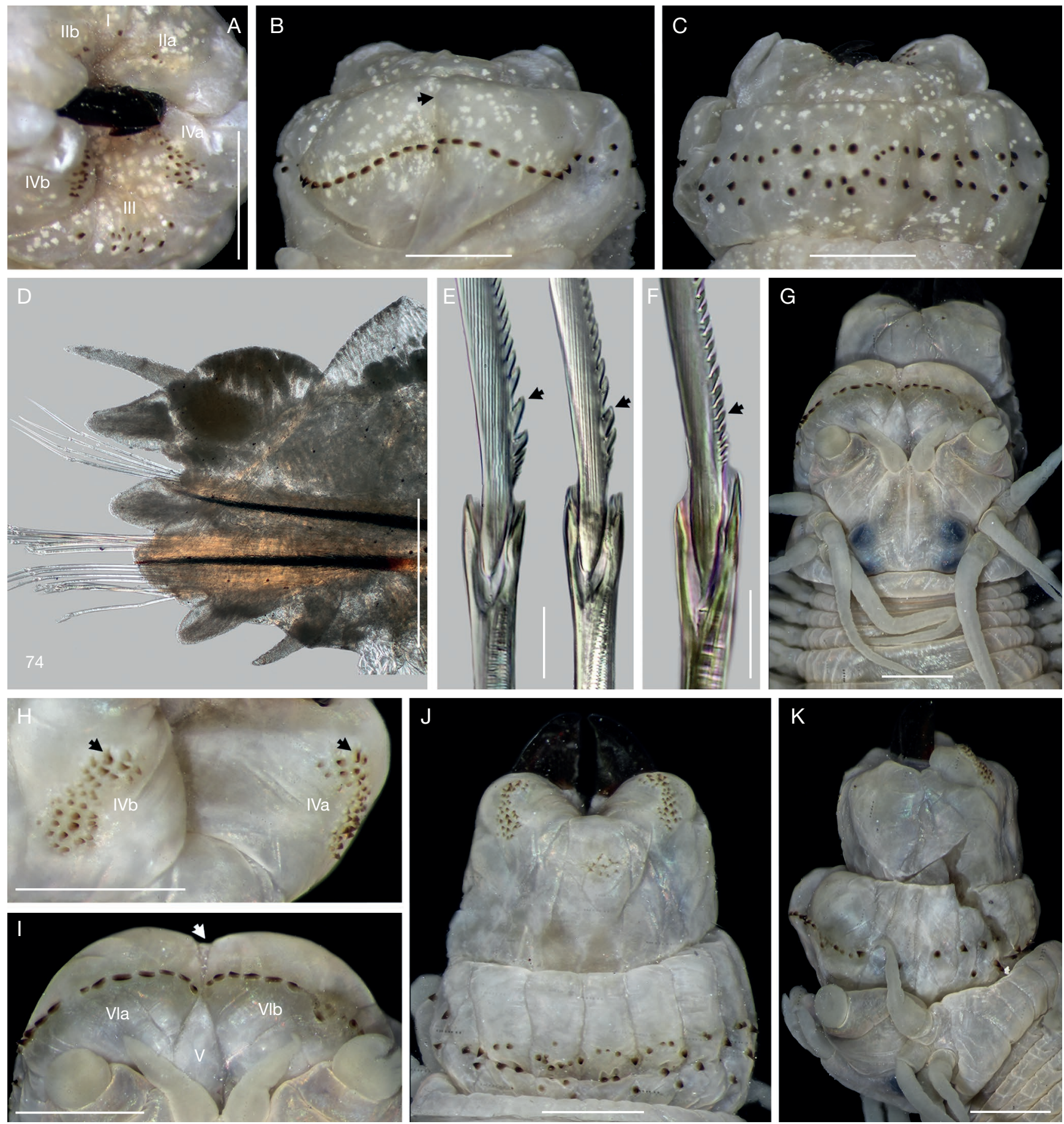

FIG. 7. - Perinereis latipalpa (Schmarda, 1861) n. comb.: A-E, topotype of Perinereis namibia Wilson \& Glasby, 1993, n. syn. (ZMB 4109b): A, maxillary ring of pharynx, frontal view; B, oral ring of pharynx, dorsal view (arrow points distal portion of $\lambda$-shaped pattern); C, same, ventral view; $\mathbf{D}$, parapodium 74 , anterior view; $\mathbf{E}$, approach to homogomph spinigers (chaet. 74), notopodial (left), neuropodial supracicular (right) (arrows point thickened, separated teeth). F-K, Perinereis vallata (Grube \& Kröyer in Grube, 1858), non-type (ZMB 3666); F, approach to neuropodial supracicular homogomph spiniger (chaet. 76) (arrow points barely thickened, evenly spaced teeth); G, anterior region, dorsal view; H, maxillary ring, frontal view (arrows point merged paragnaths); I, oral ring, dorsal view (arrow points distal portion of $x$-shaped pattern); J, pharynx, ventral view; K, same, lateral view. Scale bars: A, D, H, 0.5 mm; B, C, G, I-K, 1 mm; E, F, 15 mm.

Chaetae. Homogomph spinigers with blade bearing few first proximal teeth thickened and notoriously separated (Fig. 7E). Heterogomph spinigers present in all chaetigers, blade with proximal teeth barely thickened, evenly spaced. Falcigers in both fascicles with medium blade (b/a $=1.47-1.76$ times), serrated region $0.44-0.53$ total blade length.
Other characteristics well described and drawn in Wilson \& Glasby (1993).

REMARKS

Schmarda (1861) described 16 new species of nereidids in two genera, Heteronereis Örsted, 1843 and Nereis. In the preface of 
his work, he simultaneously referred Mastigonereis Schmarda, 1861 and Nereilepas de Blainville, 1828 as subgenera of Nereis. Although they were not represented as such in the descriptions, it was clear that he considered subdivisions in Nereis. Therefore, I herein refer the subgeneric level for Schmarda's new species, including $N$. (Nereis) latipalpa.

Schmarda (1861) described $N$. (Nereis) latipalpa using specimens collected by himself in Table Bay during his visit to Cape Town (South Africa) in February-June 1854 (see details in Appendix). The type material of $N$. (Nereis) latipalpa is still deposited at the NHMW. It consists of nine syntypes, which match the original description (Schmarda 1861); the best specimen preserved is here designated as lectotype (NMHW 769a), whereas the others as paralectotypes (NMHW 769b, $770,771)$. The size and number of chaetigers of the lectotype do not fit the specimen described by Schmarda; nevertheless, it was the only specimen dissected among the type material, agreeing with dissected parts mentioned and illustrated by Schmarda: one jaw, and one anterior (chaet. 13) and posterior (chaet. 78) parapodia, which are lost.

De Quatrefages (1866) recognized N. latipalpa as a valid species. Kinberg (1865), based on a specimen collected in Cape Town and on the description of $N$. latipalpa by Schmarda, described a new species, Neanthes latipalpa, but he was not entirely sure whether it was the same species as Schmarda's since the latter did not consider the paragnaths arrangement, a relevant feature used by Kinberg to distinguish nereidid genera and species.

Von Marenzeller (1888), after an examination of some polychaetes from Angra Pequena Bay (now as Lüderitz Bay), noticed the morphological similarities between the Namibian and Cape of Good Hope specimens. Further, he realized that $N$. (Nereis) latipalpa by Schmarda and Neanthes latipalpa by Kinberg are the same species because of the shape of the parapodia. Thus, he synonymized $N$. latipalpa Kinberg but transferred $N$. (Nereis) latipalpa Schmarda to Neanthes Kinberg, 1865, the latter following the Kinberg's classification of genera by using the pharyngeal arrangement of paragnaths.

Ehlers (1901), who certainly did not recognize as valid $\mathrm{Ne}$ anthes and other Kinberg's nereidid genera (see Ehlers 1868), examined the type material and some specimens of $N$. (Nereis) latipalpa Schmarda from Angra Pequena, regarding the species as a junior synonym of Nereis vallata (currently in Perinereis sensu Hartman 1959). Later, Willey (1904) examined the type specimen of Neanthes latipalpa and confirmed the synonymy proposed by von Marenzeller (1888), but established a trinominal name, $N$. latipalpa typica, to emphasize that it is barely different to $N$. latipalpa brevicirris (currently as Perinereis brevicirris sensu Hartman 1959). Afterward, Augener (1918) reinforced Ehlers' assumptions and considered $N$. latipalpa typica as identical to $N$. vallata, but placed in the subgenus Perinereis (sensu Augener 1913) by having, among other characters, a continuous transverse line of paragnaths on AVI.

Fauvel $(1919,1921,1932,1953)$ grouped the species morphologically similar to Perinereis nuntia, mainly characterized by having an arc of paragnaths on AVI. Within the subspecies of this group, P. nuntia var. vallata was different from the others by having $\mathrm{AI}=1-3, \mathrm{AV}=1$, most extended tentacular cirri reaching chaetigers $7-8$, and dorsal cirri subequal to dorsal ligule or slightly smaller. Fauvel considered the species as having a wide distribution (the Red Sea, India, Madagascar, South Africa, Philippine Islands, New Zealand, Australia, and Chile) based on the records of the species under several names. Also, Fauvel (1919, 1921, 1932, 1953) still retained Schmarda, Kinberg and Willey's $N$. latipalpa as a synonym of $P$. nuntia var. vallata; and since then, the three latipalpa's names have not been recognized (e.g. Hartmann-Schröder 1962; Wesenberg-Lund 1962), except by Hartman (1949, 1959), who still retained the Kinberg's species as valid in Neanthes, but details were not provided.

Hutchings et al. (1991) established three groups within Perinereis according to the number of bars on AVI; those valid species more related to $P$. nuntia were placed in the third group (AVI with numerous bars in an arc). A few years later, Wilson \& Glasby (1993) carried out a relevant study of 20 species within the $P$. nuntia species complex. They restricted the morphology of the P. nuntia complex, redescribed some of the species using type, topotype or non-type materials, such as $P$. nuntia and $P$. vallata; also, they recognized as valid some previously synonymized species, and described two new ones: Perinereis akuna (New South Wales, Australia) and P. namibia (Lüderitz Bay, Namibia). Nevertheless, the authors overlooked $N$. latipalpa since it was not included in the source of synonyms of any species, particularly $P$. vallata, neither in the appendix at the end of the document.

After the comprehensive revision of the type material of N. Nereis) latipalpa Schmarda, Neanthes latipalpa Kinberg and Neanthes latipalpa typica Willey, herein is confirmed that they belong to the same species. Furthermore, this species is here considered as valid since it is different the other species within the $P$. nuntia complex, particularly $P$. vallata. Therefore, it is reinstated as P. latipalpa (Schmarda, 1861) n. comb. Besides, $P$. namibia is regarded as a junior synonym of $P$. latipalpa n. comb., based on the original description and the revision of some topotypes formerly used by Wilson \& Glasby (1993).

Perinereis latipalpa n. comb. and P. vallata are indeed closely related species since they have a similar parapodial pattern, as well as a similar number and arrangement of paragnaths on the ventral areas of the pharynx. Nevertheless, according to my revision on the type material of $P$. latipalpa n. comb. and a specimen from Chile (Fig. 7F-K), the description of P. vallata and its accurate posterior characterizations (Ehlers 1901; Wesenberg-Lund 1962; Rozbaczylo \& Castilla 1973; Bertrán 1980; Wilson \& Glasby 1993; Sampértegui et al. 2013), the differences between these two species remain in the shape of the proximal teeth of homogomph spinigers and the AVI-V-VI pattern. In P. latipalpa n. comb., the first proximal teeth of homogomph spinigers are notoriously thick and separated (Figs 4G, $\mathrm{H} ; 5 \mathrm{~J} ; 6 \mathrm{~K} ; 7 \mathrm{E})$, whereas in $P$. vallata these are of similar size and equidistant from one another (Fig. 7F). Also, in P. latipalpa n. comb., the AVI-V-VI pattern is $\lambda$-shaped (Figs 3D, F; 5B; 6E; $7 \mathrm{~B}$ ), with the AVI overlapping AV proximally further behind the arc of paragnaths (Figs 3F; 5B; 7B); whereas in P. vallata, it is $\chi$-shaped (Fig. 7G, I), with the AVI overlapping AV proximally at the level of the arc of paragnaths (Fig. 7I). 
Perinereis latipalpa n. comb. also differs from other two closely related species of $P$. vallata: Perinereis gualpensis Jeldes, 1963 (based on the original description and characterizations of topotype specimens, e.g. Bertrán 1980; Sampértegui et al. 2013) and P. akuna Wilson \& Glasby, 1993. Perinereis gualpensis, who also shares the same type of blade of homogomph spiniger and the same pattern of AVI-V-VI as $P$. vallata, can be distinguished from P. latipalpa $\mathrm{n}$. comb. because the latter has AIII $=8-20$ and AVII-VIII $=48-66$, whereas $P$. gualpensis has AIII $=21-55$ and AVII-VIII $=27-47$. Likewise, the dorsal ligule is longer than median ligule and slightly expanded in posterior parapodia of P. latipalpa n. comb.; whereas in $P$. gualpensis, it is subequal to median ligule and not expanded in same parapodia. Furthermore, in P. latipalpa n. comb., the dorsal cirrus extends beyond the end of dorsal ligule, and it is placed on the distal quarter of the ligule, whereas in P. gualpensis the dorsal cirrus is subequal to dorsal ligule and it is located on one-half of the ligule.

On the other hand, although P. latipalpa n. comb. and $P$. akuna share the same $\lambda$-shaped pattern in AIV-V-IV, they differ in several respects. Perinereis latipalpa n. comb. has the first proximal teeth of homogomph spinigers notoriously thick and separated, whereas in P. akuna these are of similar size and equidistant from one another. The dorsal ligule is longer than median ligule and slightly expanded in posterior parapodia of $P$. latipalpa n. comb., whereas in P. akuna the dorsal ligule is subequal to median ligule and not expanded in same parapodia. Also, in P. latipalpa n. comb. the dorsal cirri extend beyond the end of dorsal ligule and it is placed on the distal quarter of the ligule; whereas in P. akuna, the dorsal cirri is subequal to dorsal ligule and it is located on one-half of the ligule. Likewise, P. latipalpa n. comb. has a lower number of paragnaths on AVII-VIII (48-66) which are arranged in 2-3 rows of small and large cones; whereas P. akuna has a larger number of paragnaths (76-191) which are arranged in more than four rows, with tiny cones in a distinct band. Finally, P. latipalpa n. comb. always lacks merged paragnaths on AIV, which are always present in P. akuna (numbering 1-5).

Wilson \& Glasby (1993) regarded the occurrence of merged paragnaths on AIV as a relevant taxonomic feature to distinguish species within the P. nuntia complex; however, this character may be present or absent in individuals of the same species (Hutchings et al. 1991; Wilson \& Glasby 1993; Park \& Kim 2007; Sampértegui et al. 2013). Concerning P. vallata, Sampértegui et al. (2013) considered this character as varying since it was only present in a few of their Chilean specimens. The specimens herein examined of $P$. latipalpa $\mathrm{n}$. comb. lack this type of paragnath, but a small merged one was present in the examined individual $P$. vallata. It is uncertain if their presence/absence on AIV of the latter species is related to size or to a particular developmental stage. Nevertheless, it is noteworthy that any of the specimens of P. latipalpa $\mathrm{n}$. comb. herein examined and many of those examined by Wilson \& Glasby (1993) as P. namibia, have merged paragnaths. For this reason, this feature should be carefully used to distinguish species within the $P$. nuntia complex.

\section{Perinereis larentukana}

(Grube in Peters, 1881), reinst., n. comb.

(Figs 1G-I; 8A-L; 9A-F)

Nereis (Neanthes) larentukana Grube in Peters, 1881: 110-111.

Neanthes larentukana - Hartman 1959: 250. — Wiktor 1980: 273.

Nereis larentukana - Hartwich 1993: 111.

Perinereis nuntia - Wilson \& Glasby 1993: 266-268, fig. 11a-g. Glasby \& Hsieh 2006: 563-565, fig. 6a-f (partim, non Savigny in Lamarck, 1818).

TYPE MATERIAL. - 7 syntypes of Nereis (Neanthes) larentukana: 1 specimen, MPW 411, labelled as "holotypus lub syntypus", in poor condition; 4 specimens, ZMB 863, labeled as "Syntypen", in good conditions; two specimens (ZMB 4002-Q), labeled as "Syntypen", in poor conditions. All collected by E. K. von Martens, from Larantuka, Flores, East Nusa Tenggara, Indonesia, no further data but see remarks and Appendix.

DiAGNOSIS. - Specimens with antennae joined, nuchal organs 3 times longer than posterior eyes, postero-dorsal tentacular cirri reaching chaetigers 2-3. Jaws with 2 canals. Maxillary ring: $\mathrm{AI}=2-3$; $\mathrm{AII}=7-9 ; \mathrm{AIII}=9-17,1$ lateral cone; $\mathrm{AIV}=20-28$, merged paragnaths absent. Oral ring: AVI-V-VI pattern, v-shaped; $A V=3-4$, paragnaths behind AVI; AVI = 4-8, arc short, regular, bars short, even, except inner one slightly longer; AVII-VIII = 26-34, 2 transverse rows, proximal with large cones. Gap between AVI and AVII-VIII broad. Dorsal cirri short, one-half length of dorsal ligule, inserted posteriorly on two-thirds of it. Dorsal ligule even throughout body, subequal to median ligule; distal lobe bluntly conical posteriorly. Ventral cirri short, digitiform. Homogomph spinigers with blade finely serrated, evenly spaced; absent in subacicular neurochaeta. Heterogomph spinigers such as notopodial; absent in a few anterior chaetigers. Heterogomph falcigers with short and medium blades.

HABITAT. - Unknown.

Type LOCALITY. — Larantuka, Flores, East Nusa Tenggara, Indonesia.

Distribution. - West Timor, East Flores (East Nusa Tenggara); Ambon (Moluccas); Besuki (East Java).

\section{DESCRIPTION}

Measurements. Syntype, ZMB 863, atoke, lacking posterior region, $\mathrm{LT}=127(216-235) \mathrm{mm}, \mathrm{L} 15=21.1(17-25.3) \mathrm{mm}$, $\mathrm{W} 15=4.3(3.6-4.6) \mathrm{mm}$, and 117 (154-192) chaetigers.

Pigmentation. Body epidermal pigmentation faded, some slight traces of pale brown pigmentation in prostomium and posterior parapodia. Brownish glandular patches in ligules, most intense posteriorly (Fig. 9E, F).

Head. Prostomium sub-pentagonal, narrow anterior end (Fig. 8A, B), 1.3 times wider than long; anterolateral sides 2 times wider than antennal diameter. Palpophores cylindrical (Fig. 8A), thick, 1.2 times longer than wide, nearly equaling entire length of prostomium; one deep wrinkle placed horizontally in one-half of palpophore. Antennae joined (Fig. 8A, B), gap one-sixth of antennal diameter; digitiform, barely sharpened tip, slightly thickened, extending backward to nearly one-half of prostomium. Eyes in sub-trapezoidal arrangement, blackish, anterior and posterior pairs well sepa- 
rated (1.6 times size of posterior; Fig. 8B); lens barely visible, purplish. Anterior pair of eyes reniform, nearly subequal to antennal diameter; lens oval, located anterolaterally, touching margin of eye, covering $50 \%$. Posterior pair of eyes rounded, subequal to anterior pair; lens rounded, located posterolaterally, not touching margin, covering $60 \%$. Nuchal organs deeply embedded, slightly oblique, notoriously long, 3 times longer than posterior eyes (Fig. 8B).

Apodous anterior segment $\&$ tentacular cirri. Apodous anterior segment 3.3 (3.3-4.2) times wider than long, 1.2 (1.21.4) times longer than chaetiger 1 . Tentacular cirri pattern: Postero-dorsal cirri 1.5 times longer than antero-dorsal ones; anterior-ventral cirri slightly smaller than postero-ventral one. Antero-dorsal cirri reaching chaetiger 1 (1-2); antero-ventral $1.2(1-1.3)$ times longer than palpophore. Postero-dorsal reaching chaetiger 3 (2-3); postero-ventral extending over prostomium to reach one-half of it. Dorsal cirrophores wrinkled, cylindrical; postero-dorsal cirrophores longest, 2.5 times length of postero-ventral cylindrical ones.

Pharynx. Not everted, previously dissected (description based on syntype with everted pharynx). Jaws blackish in distal third, then brownish; 8 (6-7) denticles, well-developed, 4 denticles ensheathed proximally, inner margin of fang flattened, equaling next 2.5 denticles; pulp cavity two-fifths length of jaw (Fig. 8C), distal apex leveling between first and second basal denticles; 2 longitudinal canals emerging from pulp cavity (Fig. 8D). Maxillary ring (Fig. 8E): paragnaths conical, none worn, reddish amber colored, slightly smaller than those in oral ring. $\mathrm{AI}=2$ (2-3), longitudinal regular line, cones subequal to the longest of AII. AIIa $=8(7-9)$, AIIb $=9(4-10)$, oblique irregular patch, two irregular rows. AIII = 13 (9-17), oval patch, three irregular transverse rows, one cone laterally isolated in each side. $\mathrm{AIVa}=21$ (21-26), $\mathrm{AIVb}=20$ (20-28), lemniscateshaped patch, maxillary portion smaller than proximal one, inner cones smallest; merged paragnaths absent. Oral ring (Figs 1G-I, 8F-H): AVI-V-VI pattern, v-shaped (Figs 1G-I, 8F); AVI not overlapping proximally AV. Paragnaths conical and shield-shaped bars, reddish and brownish amber colored. $\mathrm{AV}=3(3-4)$, equilateral triangular patch, clearly isolated from those on AVI, brownish amber, distal cone slightly bigger. $\mathrm{AVIa}=7$ (4-8), AVIb = 6 (5-7), arc of paragnaths short, regular, reddish amber, shield-shaped bars; bars short, tip barely worn, subequal except inner one slightly longer than others (Fig. 8G); ridges barely prominent, narrow, three-quarters width of palpophore. AVII-VIII = 26 (26-34), conical paragnaths, most of them placed in longitudinal wrinkles of ring (Fig. $8 \mathrm{H}$ ); single band of two main transverse rows, increasing in number dorsoventrally from 1 to 2 rows, distal one regular with mainly big, reddish amber cones, proximal row irregular, zigzagged smaller, brownish amber cones. Gap between AVI and AVIIVIII broad, as wide as three-quarters width of palpophore.

Notopodia. Dorsal cirri digitiform throughout body; slightly longer than dorsal ligule in first parapodia, smaller than it from parapodia 5, three-quarters length of ligule in anterior para- podia, one-half from median ones; cirrus longer than length of proximal lobe of dorsal ligule in first parapodia (Fig. 9A), subequal to it in anterior (Fig. 9B), smaller from median ones (Fig. 9C-F); cirri inserted on one-third in anterior parapodia (Fig. 9A, B), one-half in median (Fig. 9C-E), two-thirds in posterior ones (Fig. 9F). Dorsal ligule similar throughout body; ligule 1.5 (1.5-1.8) times width of median ligule in posterior parapodia (Fig. 9F). Distal lobe of dorsal ligule bluntly rounded in anterior parapodia, bluntly conical from median parapodia; distal lobe slightly longer than proximal one in first parapodia, subequal to it in anterior, four-fifths or three-fifths length of proximal from median ones (Fig. 9D-F). Dorsal ligule slightly shorter than median ligule in anterior parapodia (Fig. 9B), slightly longer than it from median (Fig. 9C-F). One main glandular patch in dorsal ligule, central, becoming darker and bigger from parapodia 45 ; oval, covering $25-30 \%$ in median parapodia (Fig. 9D); rounded, covering $50-60 \%$ in posterior ones (Fig. 9F). Notoacicular process poorly developed.

Neuropodia. Neuracicular ligule barely smaller than ventral throughout body; twice wider than ventral ligule in anterior parapodia, 3 times wider from median ones. Superior lobe digitiform, shorter than inferior lobe throughout body, projecting beyond end of neuracicular ligule only in first 6 parapodia (5-9), reduced from parapodia 16 (15-21). Inferior lobe rounded (Fig. 9A, B), narrowing progressively from parapodia 30 (28-33). Ventral ligule digitiform, shorter than median ligule throughout body, two-thirds length of ligule in anterior parapodia, one-half length from median ones. Ventral cirri digitiform, smaller than ventral ligule throughout body, leveling base of ligule, except in first 18 parapodia, one-half or two-fifths of ligule.

Chaetae. Notochaetae with homogomph spinigers, blade finely serrated towards toothed edge, evenly spaced. Neurochaetal supracicular fascicle with homogomph spinigers and heterogomph falcigers, both present throughout; spinigers as notopodial ones (Fig. 8I), as numerous as falcigers in same fascicle of anterior and median chaetigers, more than falcigers in posterior one; falcigers with short and medium blades (b/a $=1-1.57$ times), serrated region 0.31-0.35 of total blade length (Fig. 8J). Neurochaetal subacicular fascicle with heterogomph spinigers and heterogomph falcigers, spinigers absent in first 2 (2-7) chaetigers, falcigers present throughout body; spinigers with blade finely serrated towards toothed edge, evenly spaced, less numerous than falcigers in fascicle; falcigers with short and medium blades ( $b / a=1.05-1.62$ times), serrated region $0.33-0.44$ of total blade length (Fig. 8K).

Pygidium. Dehiscent but one complete syntype with short and thick anal cirri (Fig. 8L), as long as last 3 (2-5) chaetigers, cirrophores poorly developed.

\section{REMARKS}

Grube in Peters (1881) described Nereis (Neanthes) larentukana using specimens from Larantuka (Indonesia) and collected by von Martens in January 1863 (see details in Appendix). 

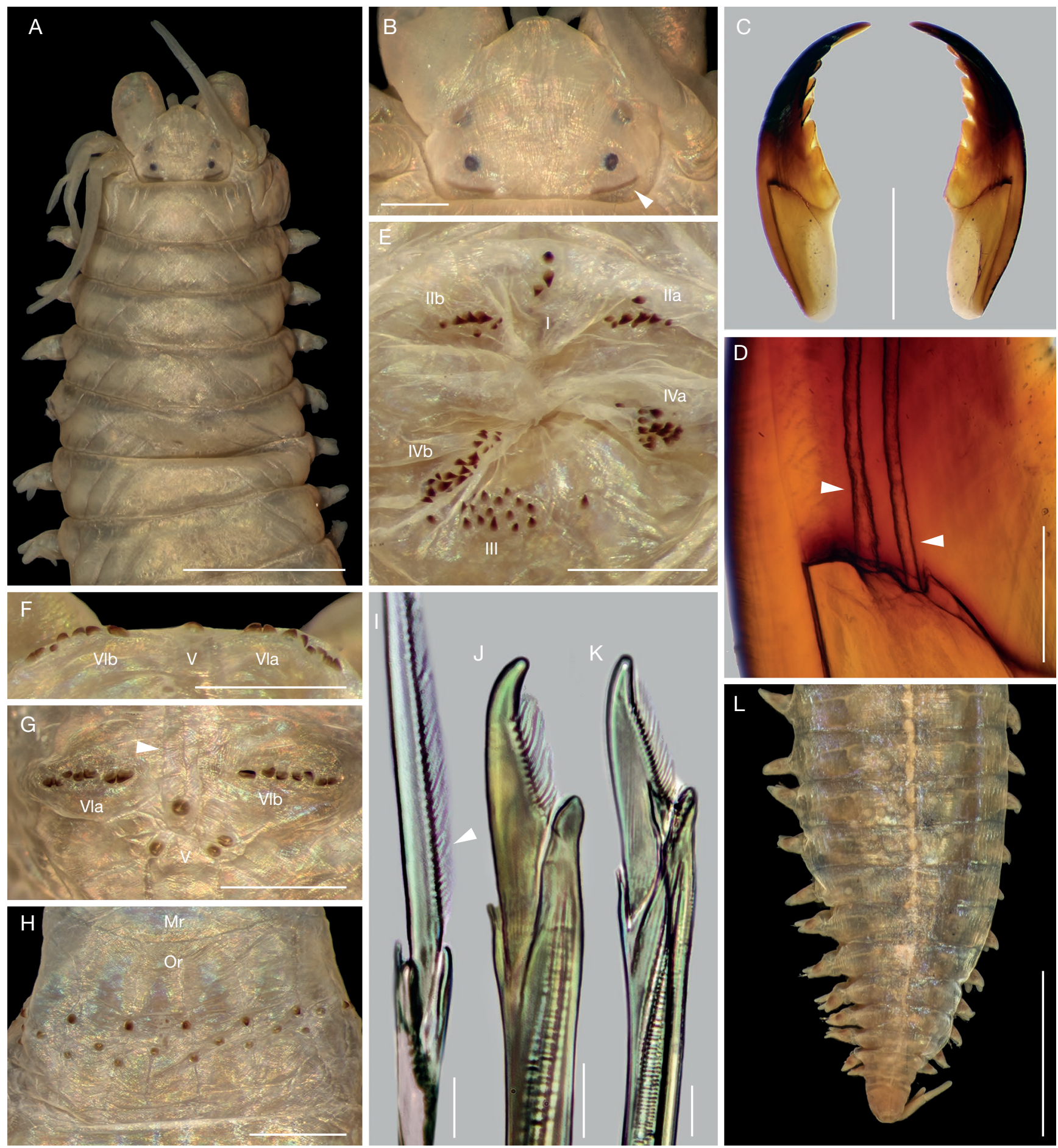

FIG. 8. - Perinereis larentukana (Grube in Peters, 1881) n. comb., syntypes (ZMB 863): A-D, I-K, from best-preserved specimen; E-H, L, from complete specimen; A, anterior region, dorsal view; B, prostomium, dorsal view (arrow points nuchal organ); C, left jaw, dorsal (left) and ventral (right) views; D, same, zoom-in, ventral view (arrows point canals); E, maxillary ring of pharynx, frontal view; F, oral ring, frontal view; $\mathbf{G}$, same, dorsal view (arrow points distal portion of $\lambda$-shaped pattern); H, same, ventral view; I, approach of notopodial homogomph spiniger (chaet. 10) (arrow points slender, evenly spaced teeth); J, neuropodial heterogomph falciger, supracicular (chaet. 10); M, same, subacicular (chaet. 10); L, posterior region, dorsal view. Scale bars: A, 3 mm; B, H, L, 1 mm; C, E-G, 0.5 mm; D, 0.1 mm; I-L, 15 4m.

The type material of $N$. (Neanthes) larentukana is currently lodged at the Museum of Natural History of the Wroclaw University (MPW) and at the ZMB (Wiktor 1980; Hartwich 1993; Glasby \& al Hakim 2017). It consists of seven syntypes that match accurately the original description that was based apparently in at least two specimens.
Grube (1874) proposed three groups within the subgenus Nereis (Lycoris); among them, a group lumping the $N$. nuntia related species, characterized by having several paragnaths in an arched row running towards the center of AV. Later, Grube in Peters (1881) considered the above concerning species in $N$. (Neanthes), which is also a member of the P. nuntia com- 
plex. It is still uncertain why Grube resumed using Neanthes as subgenus; however, it is probably that based on his 1874 work, he realized lately that $N$. nuntia group might represent other distinct but valid subgenus with Neanthes as representative. Perhaps, he followed the second group of Neanthes proposed by Kinberg (1865) for $N$. variegata (Grube \& Örsted in Grube, 1858) (currently as Pseudonereis variegata), which was regarded as having $\mathrm{AV}=3$, just like $N$. (Neanthes) larentukana. However, Kinberg (1865) misinterpreted Grube's original description of $N$. variegata on the oral ring: "annulus posterior [...] supra singulis 3 juxtapositis", transl. "posterior ring [...] 3 single dorsal (paragnaths) placed close together” (Grube \& Örsted in Grube 1858). According to Ehlers (1901), who examined the type specimen of $N$. variegata, and my revision on a topotype previously identified by Grube (ZMB 3671), the species has one large cone on $\mathrm{AV}$ and one single large compressed paragnath in each side of AVI. Intriguingly, it is noteworthy that Ehlers (1901) found, although very few, topotypes having three cones in a triangle or transverse row on AV.

The type material of $N$. (Neanthes) larentukana has not been examined since its description. Furthermore, the species has been scarcely addressed in the literature and commonly listed as Neanthes (Hartman 1959; Fauchald 1972; Wilson 1984; Salazar-Vallejo et al. 2014; Glasby \& al Hakim 2017); however, no details on its validity have been provided. After the examination of the type specimens, it is unveiled that $N$. (Neanthes) larentukana is a member of the P. nuntia species complex, mainly by having conical paragnaths on both pharyngeal rings, an arc of several shield-shaped paragnaths on AVI, notochaeta with only homogomph spinigers, and dorsal and median ligules slightly uneven throughout the body (Wilson \& Glasby 1993; Glasby \& Hsieh 2006; this study). Therefore, it is regarded as a Perinereis species, P. larentukana n. comb.

Based on the revision of the type material of P. larentukana n. comb., and compared with the redescription of $P$. nuntia herein provided, these two species differ in several features. In P. larentukana n. comb., the AVI-V-VI pattern is $v$-shaped (Fig. 1H, 8G); whereas in P. nuntia, it is $\chi$-shaped (Fig. 1D-F, 2F). In P. larentukana n. comb., the dorsal cirrus from median parapodia is digitiform, shorter than dorsal ligule (Fig. 9C-F); whereas in P. nuntia it is cirriform, notoriously longer than ligule (Fig. 2I-K). In addition, in P. larentukana n. comb., the dorsal ligule from median parapodia is bluntly conical (Fig. 9C-F), whereas in $P$. nuntia the ligule is tapered and sharply pointed (Fig. 2I-K). Furthermore, P. larentukana n. comb. lacks heterogomph spinigers in the first few anterior chaetigers, whereas in $P$. nuntia this type of chaeta is present in all chaetigers. The heterogomph falcigers in P. larentukana n. comb. are shorter $(b / a=1.05-1.62$ times) and less serrated (serrated region 0.310.44 ) than those in P. nuntia (b/a $=1.37-2.15$ times; serrated region $0.42-0.56)$. The nuchal organs are notoriously longer in P. larentukana n. comb. (3 times longer than posterior eye; Fig. $8 \mathrm{~B}$ ) than those of $P$. nuntia (subequal to posterior eyes; Fig. 2A). Likewise, P. larentukana n. comb. has two transverse rows of paragnaths on AVII-VIII (Fig. $8 \mathrm{H}$ ), increasing from 1 to 2 in dorsoventral direction; whereas, $P$. nuntia has four rows (Fig. 2E, G), increasing from 2 to 4 in the same direction.
Perinereis larentukana n. comb. has AIV = 20-28, AVI =4-8, and AVII-VIII = 26-34; whereas $P$. nuntia has AIV=14-19, AVI $=8-10$, and AVII-VIII =36-50. Complete specimens of P. larentukana n. comb. have a greater number of segments (154-192) than those of P. nuntia (109-127).

Among the species in the $P$. nuntia complex, P. larentukana n. comb. is similar to those species with dorsal cirri distinctly shorter than dorsal ligule. However, it is more closely related to $P$. heterodonta Gravier, 1899 (Djibouti) and P. quatrefagesi (Grube, 1878) (Bohol, Philippines), both previously referred as junior synonyms of P. nuntia (Wilson \& Glasby 1993). Yousefi et al. (2011) recently reinstated the former species from the synonymy based on some specimens from near to the Gulf of Oman. They considered $P$. heterodonta as different from $P$. nuntia by lacking heterogomph spinigers in anterior neuropodia, by having shorter tentacular and dorsal cirri, AV =0-1, and AVIIVIII with fewer paragnaths (further differences, see remarks of P. nuntia). However, the number of paragnaths on AIII, AIV and AVII-VIII from Iranian specimens also slightly differ from those from Djibouti. Due to these differences, the information of the original description and illustrations of $P$. heterodonta (Gravier 1899, 1902) and the posterior characterizations with specimens from the type locality (Gravier 1902; Fauvel 1919) were used to show that it differs from P. larentukana n. comb.

Despite $P$. larentukana n. comb. and $P$. heterodonta lack heterogomph spinigers in anterior chaetigers, they differ in several features. In P. larentukana n. comb., the AVI-V-VI pattern is $v$-shaped; whereas in $P$. heterodonta, it is $\lambda$-shaped. In $P$. larentukana n. comb., the antennae are joined (gap onesixth of antennal diameter), whereas in $P$. heterodonta they are separated (gap subequal to antennal diameter). In addition, P. larentukana n. comb. has AV with 3-4 conical paragnaths, AVI with 4-8 shield-shaped bars in a regular transverse row, and AVII-VIII with 26-34 cones; whereas, in P. heterodonta, the AV lacks paragnaths, the arc of AVI has 10-18 shield-shaped bars obliquely disposed, and the AVII-VIII has 18 paragnaths, some are cones and others are p-bars. Likewise, P. larentukana n. comb. lacks heterogomph spinigers only in the first 1-7 chaetigers, whereas in $P$. heterodonta are lacking at least in the first 43 chaetigers. Finally, the postero-dorsal tentacular cirri are shorter in P. larentukana n. comb. (reaching chaetigers 2-3) than in P. heterodonta (reaching chaetigers 3-6).

Regarding P. quatrefagesi, Grube (1878) briefly described the species without illustrations and based on only one poorly preserved specimen from the Philippines; however, some relevant features were provided. For instance, some of the anterior end: antennae close enough to each other, shorter than one-half of prostomium; dorsal-most tentacular reaching chaetiger 5; AI with 3 paragnaths in a longitudinal row, AII with 7 in a circular patch, AIII with a transversely oval patch and 2 isolated cones, AIV with 18 paragnaths in 2-3 rows, AV with 1 cone, AVI with 8 bars in a transverse row, and AVII-VIII with 19 in 2 rows. Likewise, some features of parapodia; short, even throughout the body; the ligules are blunt, slightly tapered, with the dorsal ligule slightly broader, longer than median one, and ventral ligule small, rounded; dorsal cirrus short, almost one-half length of dorsal ligule; and among others. 

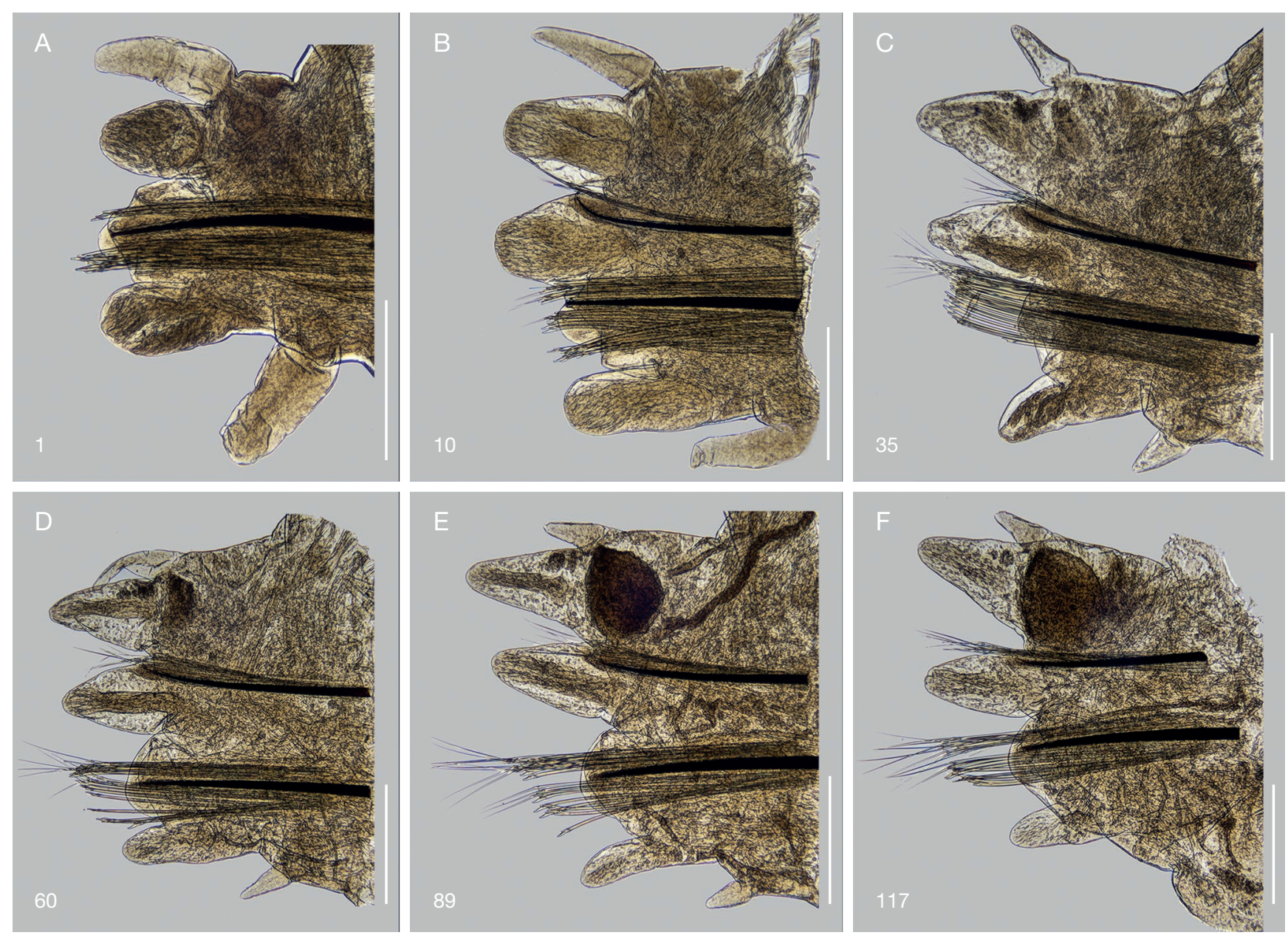

FIG. 9. - Perinereis larentukana (Grube in Peters, 1881) n. comb. best-preserved syntype (ZMB 863): A-F, parapodia, anterior view (numbers refer the chaetiger); F, with bent ventral cirri. Scale bars: $0.5 \mathrm{~mm}$.

Fauvel (1919) synonymized $P$. quatrefagesi transferring it into his group P. nuntia var. vallata. Later, Augener (1933) recognized the species as valid, but using specimens from the northern Moluccas and the description of Gnatholycastis brocki Ehlers, 1920 (Ambon Island), which was regarded as a junior synonym of $P$. quatrefagesi ever since (e.g. Hartman 1959; Salazar-Vallejo et al. 2014). However, G. brocki is characterized by having a prostomium with a slightly incised distal end, a papilliform dorsal cirrus located distally on an expanded dorsal ligule in posterior parapodia, and an arc of paragnaths on AVI (Ehlers 1920). This description, in fact, matches P. caeruleis (Hoagland, 1921) (Sulawesi) rather than $P$. quatrefagesi, a species also recognized within the $P$. nuntia complex (Wilson \& Glasby 1993). Although the revision of the type material is needed, it is possibly that G. brocki and $P$. caeruleis are the same. If this is the case, the former name has priority over the latter (ICZN 1999, Art. 23.1), which has been erroneously dated as 1920 because of the cover page of the paper, but the volume of Hoagland's work was in fact formally published until March 1921 (True \& Oesher 1947). Following the above, $P$. quatrefagesi was inaccurately regarded as valid. It is noteworthy that Glasby \& Hsieh (2006) considered $P$. caeruleis as not belonging to the P. nuntia complex, such as other two species (P. akuna and P. rhombodonta Wu, Sun \& Yang, 1981), by the presence of pyramidal paragnaths on AVI, and a band of several rows of small cones separated from larger ones on AVII-VIII.

Perinereis quatrefagesi remained somewhat unnoticed in the literature until Hylleberg et al. (1986) examined in detail several atoke and epitoke specimens from the Gulf of Thailand. Their specimens fitted accurately the original description. They were different to P. brevicirris and P. nuntia, but Nereis (Perinereis) rumphii Horst, 1919 (Banda Sea) and P. weijhouensis Wu, Sun \& Yang, 1981 (Guangxi, China) were referred as synonyms of $P$. quatrefagesi. Nevertheless, they may be regarded as independent species according to the original descriptions and Hylleberg et al. (1986) characterization.

Nereis (P.) rumphii differs from $P$. quatrefagesi in the shape of median parapodia in the epitoke female. The former species has a median ligule with an expanded lower-basal lamella and a ventral ligule with a sharp upper-basal projection, which are lacking in both ligules of $P$. quatrefagesi. Horst's description of the atoke $N$. (P.) rumphii fits that provided above for $P$. larentukana $\mathrm{n}$. comb., although the syntypes of the former species should be examined before regarding it as a junior synonym. Likewise, $P$. larentukana n. comb. differs from $P$. quatrefages $i$ 
because the former lack heterogomph spinigers in the first few anterior chaetigers, whereas this kind of chaeta is present throughout the body in $P$. quatrefagesi.

Also, P. weijhouensis is different from P. quatrefagesi because the dorsal cirrus is twice longer than dorsal ligule in posterior parapodia, the homogomph spinigers are in both neuropodial fascicles, and lacks heterogomph spinigers. Whereas in P. quatrefagesi, the dorsal cirrus is shorter than or nearly subequal to the ligule in same parapodia, the homogomph spinigers are present only in the neuropodial supracicular fascicle, and the heterogomph spinigers in the neuropodia. Perinereis weijhouensis was also synonymized with $P$. nuntia by Wilson \& Glasby (1993), but it may also be raised from this synonymy taking in account the distribution pattern of spinigers mentioned above ( $P$. nuntia similar to that in $P$. quatrefagesi); also, by having the arc of paragnaths on AVI clearly separated from each other (rows adjoining mid-dorsally in $P$. nuntia).

Wilson \& Glasby (1993) examined the holotype of P. quatrefagesi regarding it as a junior synonym of $P$. nuntia. No further details on its morphology were added to those mentioned in the original description, except that only a few chaetae are intact and the body is almost completely digested, remaining only the pale empty skin. Nevertheless, $P$. quatrefagesi herein is regarded as valid; it differs from $P$. nuntia by the length of dorsal cirrus, the mutual separation of arcs on AVI, and the number and arrangement of paragnaths on AVII-VIII. Perinereis quatrefagesi has dorsal cirrus shorter than or nearly subequal to the dorsal ligule in posterior parapodia, whereas in $P$. nuntia it is much longer (2-3 times) than ligule in same parapodia. In $P$. quatrefages $i$, the arcs of paragnaths on AVI are clearly separated from each other by the broad ridge of AV; whereas in P. nuntia, the arcs of paragnaths on AVI nearly adjoin mid-dorsally by the narrow ridge of AV. Furthermore, the AVII-VIII in P. quatrefagesi has $19-36$ paragnaths in up to 3 rows, whereas $P$. nuntia has 36-50 paragnaths in 4-5 rows.

Finally, Glasby \& Hsieh (2006) extended the description of $P$. nuntia using material from several localities of the IndoPacific, illustrating a specimen from Singapore. However, it is evident that at least the Singaporean material belongs to a species closer to P. larentukana n. comb. and P. quatrefagesi, rather than $P$. nuntia. Some features of the anterior region looks alike to $P$. larentukana n. comb./P. quatrefagesi (e.g. prostomium, antennae, dorsum of pharynx, among others). However, the slender dorsal cirrus, subequal to the dorsal ligule in posterior parapodia, and the absence of heterogomph spinigers in many anterior chaetigers, suggest that it is a different (possibly undescribed) species.

\section{Key tO SPECIES OF PERINEREIS NUNTIA COMPLEX \\ (ADAPTED FROM Wilson \& Glasby 1993, AND Glasby \& Hsieh 2006)}

This key includes all species regarded as members of the P. nuntia complex (Wilson \& Glasby 1993; Glasby \& Hsieh 2006), and other species previously regarded as not valid or even excluded. Nevertheless, some species deserve considerations since the broadly different morphological features may suggest that some species belong to a distinct group, but the phylogenetic analysis of the complex would be needed to support this idea. Glasby \& Hsieh (2006) already suggested $P$. akuna, $P$. caeruleis and $P$. rhombodonta as possibly not members of the $P$. nuntia complex by having pyramidal paragnaths on AVI and several rows of small cones separated from larger ones on AVII-VIII. However, $P$. caeruleis is strikingly different within the $P$. nuntia complex by also having a slight distal incision on the prostomium, posterior parapodia with papilliform dorsal cirrus inserted distally on an expanded dorsal ligule, short heterogomph falcigers with a much reduced serrated region throughout the body, and a large number of minute paragnaths on AIII to AVII-VIII. Also, P. maindroni Fauvel, 1943 has been considered as a member of the P. nuntia complex by having AVI with barshaped paragnaths in a transverse row. However, it is the only species within the complex bearing a notoriously elongated digitiform dorsal ligule in median parapodia, well-developed notopodial prechaetal and neuropodial postchaetal lobes, and a dorsal cirrus basally attached in all parapodia (Fauvel 1943). Despite Glasby \& Hsieh (2006) diagnosed the complex as lacking these lobes, they still recognized $P$. maindroni as a $P$. nuntia-like species.

1. Dorsal ligule elongated in median parapodia; notopodial prechaetal and neuropodial postchaetal lobes developed .............................................................................................. P. maindroni Fauvel, 1943 Dorsal ligule not elongated in all parapodia; notopodial prechaetal and neuropodial postchaetal lobes not developed . 2

2(1). Dorsal ligule broadly expanded in posterior parapodia; AVI with two arcs of paragnaths; AII without paragnaths; AV with more than 30 paragnaths; AVII-VIII with more than 200 paragnaths

P. caeruleis (Hoagland, 1921)

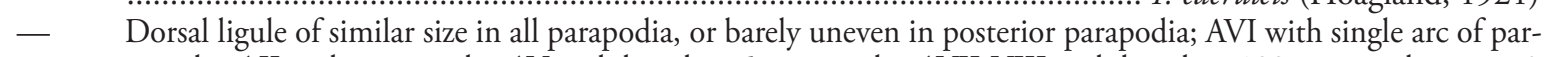
agnaths; AII with paragnaths; AV with less than 5 paragnaths; AVII-VIII with less than 199 paragnaths ........ 3

3(2). Homogomph spinigers present in subacicular fascicle of neuropodia; heterogomph spinigers absent ..... 4 Homogomph spinigers absent in subacicular fascicle of neuropodia; heterogomph spinigers present at least from median chaetigers . 
5(3). AVII-VIII with a band of large cones and a band of numerous minute cones

- AVII-VIII without an additional band of minute cones

6(5). AVI with pyramidal paragnaths; AVII-VIII with some paragnaths in rhomboidal arrangement; AIV without merged paragnaths .................................................................... P. rhombodonta Wu, Sun \& Yang, 1981 AVI with shield-shaped bars; AVII-VIII with paragnaths in regular transverse arrangement; AIV with 2-4 merged paragnaths ..................................................................... P. akuna Wilson \& Glasby, 1993

7(5). AIV with merged paragnaths 8

- AIV without merged paragnaths (cones only) 10

8(7). AIV with more than 10 merged paragnaths; AIII with more than 40 cones. P. majungaensis Fauvel, 1921

- AIV with less than 5 merged paragnaths; AIII with less than 35 cones

9(8). AVI with $8-18$ paragnaths P. vallata (Grube \& Kröyer in Grube, 1858), partim AVI with 2-4 paragnaths P. viridis Glasby \& Hsieh, 2006

10(7). Ridges of AVI distally separated from each other (AVI-V-VI patterns $\pi$-shaped; Fig. 1D-L) 11

- Ridges of AVI distally and sub-medially coalesced (AVI-V-VI pattern $\lambda$-shaped; Fig. 1A-C) 19

11(10). Ridges of AVI sub-medially markedly separated from each other (AVI-V-VI patterns oc-shaped or v-shaped; Fig. 1G-L)

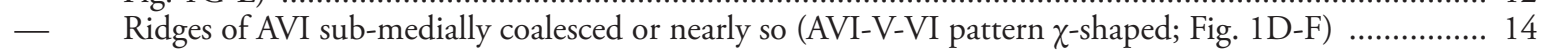

12(11). AVI-V-VI with oc-shaped pattern (concave furrows; Fig. 1J-L); dorsal cirri cirriform, long; AII with more than 17 paragnaths

P. shikueii Glasby \& Hsieh, 2006 AVI-V-VI with $v$-shaped pattern (parallel furrows; Fig. 1G-I); dorsal cirri digitiform, short in medial and posterior parapodia; AII with up to 10 paragnaths 13

13(12). Heterogomph spinigers absent in few first anterior chaetigers; natatory parapodia of epitokous female with additional expanded lamella in median ligule, sharp projection in ventral ligule

P. larentukana (Grube in Peters, 1881) n. comb.

- $\quad$ Heterogomph spinigers present in all chaetigers; natatory parapodia of epitokous female lacking additional lamella in median ligule or projections in ventral ligule ............................. P. quatrefagesi (Grube, 1878)

14(13). Dorsal cirrus about 1.5 times longer than dorsal ligule in anterior parapodia, increasing to 2-4 times its length posteriorly

- Dorsal cirrus not extending or only barely extending beyond end of dorsal ligule throughout ............. 17

15(14). AVI with very uneven-length bars (outermost longest)

— AVI with short even-length bars (outermost only slightly longer if at all) ...................................... 16

P. wilsoni Glasby \& Hsieh, 2006

16(15). AVII-VIII with less than 20-27 paragnaths, arranged in 1-2 transversal rows; AVI with 3-4 paragnaths; AIII with 6-10 paragnaths; AV with 1 paragnaths

P. ponuiensis Augener, 1924

- AVII-VIII with more than 36-50 paragnaths, arranged in 4-5 transversal rows; AVI with 8-10 paragnaths; AIII with 11-19 paragnaths; AV with 2-4 paragnaths P. nuntia (Savigny in Lamarck, 1818)

17(14). AVI with very uneven-length bars (outermost much longer) .......... P. mictodonta (von Marenzeller, 1879)

- AVI with short even-length bars (some only slightly longer if at all)

18(17). Dorsal ligule of even size along body, not projecting beyond end of median ligule in posterior parapodia; AV with paragnaths (when present) placed posteriorly to those of AVI ............. P. gualpensis Jeldes, 1963

- Dorsal ligule barely uneven in posterior parapodia, projecting beyond end of median ligule in posterior parapodia; AV with paragnaths (when present) nearly in conjunction to those of AVI P. vallata (Grube \& Kröyer in Grube, 1858), partim.

19(10). AVII-VIII with more than 50 paragnaths in 4-5 transverse rows P. brevicirris (Grube, 1866)

- AVII-VIII with up to 35 paragnaths in 2-3 transverse rows

20(19). Blades of homogomph spinigers with proximal teeth slender, evenly spaced; heterogomph spinigers absent in anterior chaetigers; gap between AVI and VIII-VIII, broad (as wide as palpophore); AVI with arc of paragnaths sited somewhat oblique ..... P. heterodonta Gravier, 1899

- Blades of homogomph spinigers with proximal teeth notoriously thickened, separated; heterogomph spinigers present throughout body; gap between areas VI and VIII-VIII, narrow (as wide as palpostyle); AVI with arc of paragnaths sited entirely transverse P. latipalpa (Schmarda, 1861) n. comb. 
TABLE 1. - Available names of valid and synonymized species within the 'Perinereis nuntia' complex.

\begin{tabular}{|c|c|c|c|}
\hline Original combination & Current combination & References on current status & Type locality \\
\hline Heteronereis caeruleis Hoagland, 1921 & P. caeruleis & Valid (Wilson \& Glasby 1993) & Limbe Strait, Philippines \\
\hline Lycoris nuntia Sav & $\begin{array}{l}\text { P. nuntia (Savigny in Lamarck, } \\
\text { 1818) }\end{array}$ & $\begin{array}{l}\text { Valid (Fauvel 1919; Wilson \& Glasby } \\
\text { 1993) }\end{array}$ & Suez Canal, Red Sea \\
\hline Neanthes latipalpa Kinberg, 1865 & $\begin{array}{l}\text { P. latipalpa n. comb. } \\
\text { (Schmarda, 1861) }\end{array}$ & Junior synonym (this study) & Cape Town, South Africa \\
\hline Neanthes latipalpa typica Willey, 1904 & P. latipalpa n. comb. & Junior synonym (this study) & Cape Town, $\subseteq$ \\
\hline 878 & P. quatrefagesi & 986; this study) & \\
\hline $\begin{array}{l}\text { Nereis (Neanthes) larentukana Grube in } \\
\text { Peters, } 1881\end{array}$ & P. larentukana n. comb. & Valid (this study) & $\begin{array}{l}\text { Larantuka, Flores, } \\
\text { Indonesia }\end{array}$ \\
\hline Nereis (Nereilepa) brevicirris Grube, 1867 & P. brevicirris & Valid (Hylleberg et al. 1986; this study) & $\begin{array}{l}\text { () St. Paul Island, Indian } \\
\text { Ocean }\end{array}$ \\
\hline Nereis (Nereilepa) pacifica Schmarda, 1861 & $\begin{array}{l}\text { P. vallata (Grube \& Kröyer in } \\
\text { Grube, 1858) }\end{array}$ & $\begin{array}{l}\text { Junior synonym (Hartmann-Schröder } \\
\text { 1962) }\end{array}$ & Auckland, New Zealand \\
\hline $\begin{array}{l}\text { Nereis (Nereilepa) vallata Grube \& Kröyer in } \\
\text { Grube, } 1858\end{array}$ & P. vallata & $\begin{array}{l}\text { Valid (Wilson \& Glasby 1993; this } \\
\text { study) }\end{array}$ & Valparaiso, Chile \\
\hline Nereis (Nereis) latipalpa Schmarda, 1861 & P. latipalpa n. comb. & Valid (this study) & , South Africa \\
\hline Nereis (Nereis) maculata Schm & P. vallata & $\begin{array}{l}\text { Junior synonym (Hartmann-Schröder } \\
\text { 1962b) }\end{array}$ & Chile \\
\hline Nereis (Perinereis) binongkae Horst, 1924 & P. binongkae & Perhaps valid (Hartman 1959) & $\begin{array}{l}\text { lau Binongko, } \\
\text { רesia }\end{array}$ \\
\hline $\begin{array}{l}\text { Nereis (Perinereis) heter } \\
\text { mictodontoides Auger }\end{array}$ & P. nuntia & synonym (Wilson \& Glasby & $\begin{array}{l}\text { Shark Bay, Denham, } \\
\text { Western Australia }\end{array}$ \\
\hline Nereis (Perinereis) ponui & $P . R$ & Valid (Wilson \& Glasby 1993) & Auckland, New Zealand \\
\hline Nereis (Perinereis) rumphii Horst, 1919 & $P$. larentukana n. comb. & Possible junior synonym (this study) & Banda Sea, Indonesia \\
\hline Nere & & lid (this study) & $\operatorname{Rec}$ \\
\hline Nere & P. $r$ & \& Glasby 1993; Glasby \& & \\
\hline Perinereis akuna Wilson \& Glasby, 1993 & P. akuna & Valid (Wilson \& Glasby 1993) & $\begin{array}{l}\text { Sydney, New South } \\
\text { Wales, Australia }\end{array}$ \\
\hline $\begin{array}{l}\text { Perinereis broomensis Hartmann-Schröder, } \\
1979\end{array}$ & P. nuntia & asby 1993) & $\begin{array}{l}\text { Broome, Western } \\
\text { Australia }\end{array}$ \\
\hline Perinereis gualpensis Jeldes, 1963 & P. gualpensis & $\begin{array}{l}\text { Valid (Bertrán 1980; Wilson \& Glasby } \\
\text { 1993) }\end{array}$ & Fundo Gualpen, Chile \\
\hline Peri & & $t$ al. 2011) & \\
\hline & & v & \\
\hline Perir & & 93) & $\mathrm{Ka}$ \\
\hline Perinereis namibia Wilson \& Glasby, 1993 & P. latipalpa $\mathrm{n}$ & tudy) & Lüderitz, Namibia \\
\hline Perinereis neocaledonica Pruvot, 1930 & P. caeruleis & $\begin{array}{l}\text { Possibly junior synonym (Wilson \& } \\
\text { Glasby 1993) }\end{array}$ & New Caledonia \\
\hline Perinereis nuntia djiboutiensis Fauvel, 1919 & P. nuntia & $\begin{array}{l}\text { Junior synonym (Wilson \& Glasby } \\
\text { 1993) }\end{array}$ & Djibouti, Gulf of Aden \\
\hline Per & & Valid (Wilson \& Glasby 1993) & $\mathrm{Ma}$ \\
\hline $\begin{array}{l}\text { Perinereis rhombodonta Wu, Sun \& Yang, } \\
1981\end{array}$ & P. rhombodonta & $\begin{array}{l}\text { Valid (Wilson \& Glasby 1993; Glasby \& } \\
\text { Hsieh 2006) }\end{array}$ & Guangdong, China \\
\hline Perinereis shikueii Glasby \& Hsieh, 2006 & P. s & Valid (Glasby \& Hsieh 2006) & Taipei, Taiwan \\
\hline Perinereis viridis Glasby \& Hsieh, 2006 & $P$. viridis & Valid (Glasby \& Hsieh 2006) & $\begin{array}{l}\text { Labrador Park, } \\
\text { Singapore }\end{array}$ \\
\hline $\begin{array}{l}\text { Perinereis weijhouensis Wu, Sun \& Yang, } \\
1981\end{array}$ & P. weijhouensis & Valid (this study) & Guangxi, China \\
\hline Perinereis wilsoni Glasby \& Hsieh, 2006 & P. wilsoni & Valid (Glasby \& Hsieh 2006) & Taipei, Taiwan \\
\hline
\end{tabular}

\section{DISCUSSION}

The studies on the $P$. nuntia species complex held earlier by Fauvel (Fauvel 1919, 1921, 1932, 1953), and more recently by Wilson \& Glasby (1993) and Glasby \& Hsieh (2006), onset the morphological delimitations among the species in the complex. They pointed out several relevant features to distinguish closely related species, such as the occurrence of merged paragnaths on AIV, the presence of an additional band of minute paragnaths on AVII-VIII, the absence of heterogomph spinigers in anterior chaetigers, the proximity of paragnaths on AV to those on the AVI, among others. Also, in this study, some novel and additional features formerly overlooked in these works but previously used in other nereidid studies to distinguish species, were also considered. For instance, the AVI-V-VI pattern, the width of the gap between AVI and AVII-VIII, the presence of p-bars on AVII-VIII, the presence of homogomph spinigers in both neuropodial fascicles, the size and shape of proximal teeth in homogomph spinigers, the distance between antennae, the number of canals in the jaws, and the length of the nuchal organs.

All these features together were used to compare the morphology of $P$. latipalpa n. comb., P. larentukana n. comb. and $P$. nuntia sensu stricto with the currently known $P$. nuntia-like 
species. As a consequence, the former two species were reinstated based on the type material, and the latter was restricted using some Red Sea specimens. Nevertheless, it is noteworthy that some other species formerly regarded as junior synonyms within the $P$. nuntia complex may also be treated as valid when comparing the original description, the re-descriptions, and/or the characterizations of topotype materials using the features above mentioned. That is the case for $P$. weijhouensis, P. quatrefagesi, and P. brevicirris, distinguishing features can be seen in the key, and in the remarks section of P. larentukana n. comb. Therefore, these species are herein raised from the synonymy, but a detailed revision of them should be carried out to confirm their status.

The $P$. nuntia complex comprises 20 valid species (Table 1 ). However, similar to the hitherto of species herein reinstated, some others are still pendent of a comprehensive revision of the type material taking into consideration those features proposed above to confirm their taxonomic status. Likewise, it is not ruled out that some other species are still buried in the historical literature, especially in those former works were many species of nereidids from worldwide areas were briefly described and poorly or non-illustrated (e.g. Savigny in Lamarck 1818; Savigny 1822; Schmarda 1861; Kinberg 1865; de Quatrefages 1866; several by Grube); as was the case of $P$. latipalpa n. comb. and P. larentukana n. comb. Thus, before describing new species and hence increasing the list of names, it is essential to keep in mind that there are still several species remaining to be re-discovered. For instance, a shallow review of a few original descriptions suggests that Nereis ehrenbergi Grube, 1868 (Red Sea) might belong to the P. nuntia complex by having an arc of paragnaths on AVI (Grube 1868), which in fact seems closer to P. heterodonta, also from the same region. Likewise, Nereis (Nereilepas) pacifica Schmarda, 1861 (New Zealand) has been regarded as a synonym of $P$. vallata (Chile) since Ehlers (1904), who also synonymized Nereis latipalpa (South Africa) and Nereis brevicirris (St. Paul Island) with Nereis vallata (nowadays in Perinereis). However, as was noted above, the latter two species are different from $P$. vallata and recognized as valid. The same situation may occur with $N$. (Nereilepas) pacifica, an accurate comparison of the type material of both synonymized species would be desirable to clarify their status.

\section{Acknowledgements}

I sincerely appreciate the support and facilities of the curators and collection managers who kindly received me in their workplaces: Birger Neuhaus and Antje Schwiering (ZMB), Emma Sherlock (NHMUK), Helmut Sattmann and Stefan Szeiler (NMHW), and Tarik Meziane (MNHN). Jolanta Jurkowska (MPW), Lena Gustavsson (SMNH), and Leslie Harris and Kirk Fitzhugh (LACM-AHF) generously gave some specimens on loan. I also thank Helmut Sattmann for sharing his knowledge on Schmarda's life and type specimens. My sincere gratitude goes to Birger Neuhaus, Hiroshi Yamasaki (ZMB), Isabel C. Molina-Acevedo (ECOSUR), Emma Sherlock and Helmut Sattmann whose charming personalities made my research stays more pleasant and comfortable. The careful reading and useful recommendations by Chris Glasby, Luis F. Carrera-Parra, Anne Mabille, and an anonymous reviewer resulted in a much-improved final contribution. During the research stays, I was supported by funding from the DAAD Short-Term Grants (91673478), CONACYT Becas Mixtas (291062, 291212), and ECOSUR.

\section{REFERENCES}

Álvarez-Campos P., Gil J. \& San Martín G. 2015. — Unveiling the Rosetta Stone of syllids: redescription and neotype designation of Syllis monilaris Savigny in Lamarck, 1818, type species of type genus of family Syllidae Grube, 1850 (Annelida). Zootaxa 4040 (3): 317-330. https://doi.org/10.11646/zootaxa.4040.3.4 Audouin J. V. \& Milne-Edwards H. 1833. - Classification des Annélides et description de celles qui habitent les côtes de la France. Annales des sciences naturelles, Paris, séries 1, 29: 195-269. https://doi.org/10.5962/bhl.part.8010

Augener H. 1913. - Polychaeta I, Errantia, in Michaelsen W. \& Hartmeyer R. (eds.), Die Fauna Südwest-Australiens. Ergebnisse der Hamburger südwest-australischen Forschungsreise 1905. Volume IV, Lieferung 5. Gustav Fischer, Jena: 65-304. https:// www.biodiversitylibrary.org/item/31515\#page/3

Augener H. 1918. - Polychaeta. Beitrage zur Kenntnis der Meeresfauna Westafrikas 2 (2): 67-625. https://doi.org/10.5962/bhl.title.7400

Augener H. 1922. - Polychaeta Revision der australischen Polychaeten-Typen von Kinberg. Arkiv for Zoologi 14 (8): 1-42. http:// biostor.org/reference/117359

Augener H. 1924. - Papers from Dr Th. Mortensen's Pacific Expedition 1914-16. XVIII. Polychaeta II. Polychaeten von Neuseeland. I. Errantia. Videnskabelige Meddelelser fra Dansk naturhistorisk Forening i Köbenhavn 75: 241-441. http://direct. biostor.org/reference/235597

Augener H. 1933. - Polychaeten aus den Zoologischen Museen von Leiden und Amsterdam. II. Zoologische Mededeelingen uitgegeven door het Rijks Museem van Natuurlijke Historie te Leiden 16 (2): 107-128. http://www.repository.naturalis.nl/document/149941

AzIz N. D. 1938. - Fauna of Karachi. 2. Polychaetes of Karachi. Memoirs of the Department of Zoology, Panjab University 1: 18-52.

BAKKEN T. 2007. - Revision of Pseudonereis (Polychaeta, Nereididae). Zoological Journal of the Linnean Society 150 (1): 145-176. https://doi.org/10.1111/j.1096-3642.2007.00289.x

BAKKEN T. \& Wilson R. S. 2005. - Phylogeny of nereidids (Polychaeta, Nereididae) with paragnaths. Zoologica Scripta 34: 507-547. https://doi.org/10.1111/j.1463-6409.2005.00200.x

Bakken T., Glasby C. J. \& Wilson R. S. 2009. - A review of paragnath morphology in Nereididae (Polychaeta). Zoosymposia 2: 305-316. https://doi.org/10.11646/zoosymposia.2.1.21

Ben-Eliah M. N. 1972. - Polychaeta errantia of the Suez Canal. Israel Journal of Zoology 21: 189-203.

Ben-Eliah M. N. 1991. - Nereididae of the Suez Canal — Potential lessepsian migrants? Bulletin of Marine Science, 48 (2): 318-329.

Bertrán C. 1980. - Análisis taxonómico de Perinereis gualpensis Jeldes y Perinereis vallata Grube (Annelida, Polychaeta) en el estuario del Rio Lingue, Chile. Studies on Neotropical Fauna and Environment 15: 81-89. https://doi.org/10.1080/01650528009360566

Claparède E. 1870. - Les Annélides Chétopodes du Golfe de Naples. Supplément. Mémoires de la Société de physique et d'histoire naturelle de Genève 20 (2): 365-542. https://www.biodiversitylibrary.org/item/18576\#page/13

Conde-Vela V. M. \& Salazar-Vallejo S. I. 2015. - Redescriptions of Nereis oligohalina (Rioja, 1946) and N. garwoodi González-Escalante \& Salazar-Vallejo, 2003 and description of N. confusa sp. N. (Annelida, Nereididae). ZooKeys 518: 15-49. https://doi.org/10.3897/zookeys.518.9564 
DAY J. H. 1967. - A monograph of the Polychaeta of Southern Africa. Pt. 1 Errantia. British Museum (Natural History) Publications, 656, 458 p. https://www.biodiversitylibrary.org/item/35415\#page/7

De Quatrefages A. 1866. - Histoire naturelle des Annelés marins et d'Eau douce: Annélides et Géphyriens. Tome Premier. Librairie Encyclopédique de Roret, Paris, 588 p. https://www.biodiversitylibrary.org/item/214290\#page/7

De Saint-Joseph A. A. 1898. - Les Annélides Polychètes des côtes de France (Manche et Océan). Annales des Sciences Naturelles, Zoologie, Série 8, 5: 209-464. http://hdl.handle.net/1908/4519

De SainT-Joserh A. A. 1906. - Les Annélides Polychètes des côtes de France (Océan et côtes de Provence). Annales des sciences naturelles, Paris, Série 9, 3: 145-258. http://hdl.handle. net $/ 1908 / 4520$

EHLERS E. 1868. - Die Borstenwürmer (Annelida Chaetopoda) nach Systematischen und Anatomischen Untersuchungen. Verlag von Wilhelm Engelmann, Leipzig, xx + 269, 269-748. https:// doi.org/10.5962/bhl.title.2081

EHLERS E. 1897. - Zur Kenntnis der ostafrikanischen Borstenwurmer. Nachrichte de Königlichen Gesellschaft der Wissenschaften Goettingen Mathematisch-Physikalische Klasse 2: 158-176. http://www. digizeitschriften.de/dms/resolveppn/?PID=GDZPPN002497816 (last consultation 28/10/2019).

EHLERS E. 1901. - Die Polychaeten des magellanischen und chilenischen Strandes: Ein faunistischer Versuch. Festschrift zur Feier des 150jährigen Bestehens der Königlichen Gesellschaft der Wissenschaften zu Göttingen. Weidmannsche, Berlin, 232 p.

EHLERS E. 1904. - Neuseeländische Anneliden. Abhandlungen der Königlichen Gesellschaft der Wissenschaften zu Göttingen Mathematisch-Physikalische Klasse. Neue Folge 3 (1): 1-80. http:// biostor.org/reference/144682

EHLERS E. 1905. - Anneliden der Sammlung Schauinsland (Ergebnisse einer Reise nach dem Pacific. Schauinsland 1896/97). Zoologische Jahrbücher, Abteilung für Systematik, Geographie und Biologie der Tiere 22 (3): 281-302. http://biostor.org/reference/181321

EHLERS E. 1920. - Polychaeten von Java und Amboina. Ein Beitrag zur Kenntnis der malaiischen Strandfauna. Abhandlungen der koeniglichen Gesellschaft der Wissenschaften zu Goettingen, Series neue folge 10 (7): 1-73.

EhrenberG C. G. 1828. - Reisen in Aegypten, Libyen, Nubien und Dongala. Erster Band. Erste Abtheilung. Mit einer Landcharte und einer Ansicht des Libyschen Wüsten-Abfalls. Ernst Siegfried Mittler; Posen and Bromberg, Berlin, $162 \mathrm{p}$.

FAUCHALD K. 1972. - Benthic polychaetous annelids from deep water off western Mexico and adjacent areas in the Eastern Pacific Ocean. Allan Hancock Monographs in Marine Biology 7: 1-575. https://repository.si.edu/handle/10088/6207

Fauvel P. 1911. - Annélides Polychètes du Golfe Persique recueillies par M. M. Bogoyawlensky. Archives de Zoologie Expérimentale et Générale, 5e série, 6: 353-439. https://www.biodiversitylibrary. org/item/29668\#page/483

FAUVEL P. 1914. - Annélides polychètes non-pélagiques provenant des campagnes de l'Hirondelle et de la Princesse-Alice (1885-1910). Résultats des campagnes scientifiques accomplies par le Prince Albert I 46: 1-432. https://www.biodiversitylibrary.org/ item/18640\#page/9

FaUVEL P. 1918. - Annélides Polychètes des côtes d'Arabie récoltées par M. Ch. Pérez. Bulletin du Muséum d'Histoire Naturelle 24 (5): 329344. https://www.biodiversitylibrary.org/item/137427\#page/353

FAUVEL P. 1919. - Annélides polychètes de Madagascar, de Djibouti et du Golfe Persique. Archives de Zoologie expérimentale et Générale 58: 315-473. https://biostor.org/reference/59085

Fauvel P. 1921. - Polychètes de Madagascar, du Museum d'Histoire naturelle recueillies par M. le Dr W. Kaudern en 1912. Arkiv for Zoologi 13: 1-32. https://www.biodiversitylibrary.org/ item/30139\#page/597

FAUVEL P. 1927. - Rapport sur les Annélides Polychètes errantes. Zoological results of the Cambridge Expedition to the Suez Canal,
1924. The Transactions of the Zoological Society of London 22, 4 (1): 411-437. https://doi.org/10.1111/j.1096-3642.1927.tb00203.x

Fauvel P. 1932. - Annelida Polychaeta of the Indian Museum, Calcutta. Memoirs of the Indian Museum 12: 1-262. http://www. southasiaarchive.com/Content/sarf.100012/203784/002 (last consultation 28/10/2019).

Fauvel P. 1943. - Deux Polychètes nouvelles. Bulletin du Muséum d'Histoire Naturelle, Paris, Série 2, 15 (4): 200-202. https://biostor.org/reference/208956

FaUvel P. 1953. - The fauna of India including Pakistan, Ceylon, Burma and Malaya. Annelida Polychaeta. The Indian Press Ltd, Allahabad, 507 p. http://faunaofindia.nic.in/php/fi/fi_books_toc.php?book_ id $=0568$ type $=$ fi\&book_title $=$ Annelida $+\% 3 \mathrm{~A}+$ Polychaeta (last consultation 28/10/2019).

GLASBY C. J. 2015. — Nereididae (Annelida: Phyllodocida) of Lizard Island, Great Barrier Reef, Australia. Zootaxa 4019 (1): 207-239. https://doi.org/10.11646/zootaxa.4019.1.11

Glasby C. J. \& AL HaKIM I. 2017. - History of collection and discovery of polychaetes (Annelida), including a bibliography, from the Indo-Malay-Philippines Archipelago and surrounding seas. Raffles Bulletin of Zoology 65: 545-558. https://lkcnhm.nus. edu.sg/rbz/volume-65/ (last consultation 28/10/2019).

Glasby C. J. \& Hsieh H.-L. 2006. — New species and new records of the Perinereis nuntia species group (Nereididae: Polychaeta) from Taiwan and other Indo-West Pacific shores. Zoological Studies 45 (4): 553-577. http://zoolstud.sinica.edu.tw/Journals/45.4/553. html (last consultation 28/10/2019).

Gravier C. 1899. - Contribution à l'étude des annélides polychètes de la Mer Rouge. Bulletin du Muséum d'Histoire Naturelle 5 (5): 234-244. https://doi.org/10.5962/bhl.part.6290

Gravier C. 1902. - Contribution à l'étude des annélides polychètes de la Mer Rouge (Suite). Nouvelles Archives du Muséum d'Histoire Naturelle, Paris, 4e série 3: 147-268. https://www. biodiversitylibrary.org/item/111884\#page/159

Grube A. E. 1851. - Die Familien der Anneliden, mit Angabe ihrer Gattungen und Arten. Ein systematischer Versuch. Nicolai'schen Buchhandlung, Berlin. 164 p. https://doi.org/10.5962/bhl. title. 46818

Grube A. E. 1858. - Annulata örstediana. Enumeratio Annulatorum, quae in itinere per Indiam occidentalem et Americam centralem annis 1845-1848 suscepto legit cl. A. S. Örsted, adjectis speciebus nonnullis a cl. H. Kröyero in itinere ad Americam meridionalem collectis, (Fortsættelse [continued]) [2. Familia Euniceae - F. Syllidea]. Videnskabelige Meddelelser fra Dansk Naturhistorisk Forening for 1857: 158-186. https://www.biodiversitylibrary.org/item/110674\#page/159

GRuBE A. E. 1866. - Beschreibungen neuer von der Novara-Expedition mitgebrachter Anneliden und einer neuen Landplanarie. Verhandlungen der kaiserlich-königlichen zoologisch-botanischen Gesellschaft in Wien 16: 173-184. https://www.biodiversitylibrary. org/page/26723400\#page/345

GRUBE A. E. 1868. - Eine Reihe neuer Anneliden und deren Abbildungen. Jahres-Bericht der Schlesischen Gesellschaft für vaterländische Cultur 45: 50-52. https://www.biodiversitylibrary.org/ item/177205\#page/62

Grube A. E. 1874. - Die Familie der Lycorideen und die Aufstellung von Gruppen in der Gattung Nereis. Jahres-Bericht der Schlesischen Gesellschaft für vaterländische Cultur 51: 56-72. https:// www.biodiversitylibrary.org/item/118508\#page/76

Grube A. E. 1878. - Annulata Semperiana. Beitrage zur Kenntnis der Annelidenfauna der Philippinen nach den von Herrn Prof. Semper mitgebrachten sammlungen. Mémoires de l'Académie Impériale des Sciences de St. Pétersbourg, 7e série, 25: 1-300. https:// doi.org/10.5962/bhl.title.85345

HANLey J. R. 1991. — Revision of the genus Paralepidonotus Horst, 1915 (Polychaeta: Polynoidae). Invertebrate Taxonomy 4: 10531075. https://doi.org/10.1071/IT9901053

HaRTMAN O. 1949. - The marine annelids erected by Kinberg 
with notes on some other types in the Swedish State Museum. Arkiv för Zoologi 42A: 1-137.

HARTMAN O. 1959. - Catalogue of the polychaetous annelids of the world. Allan Hancock Foundation Publications, Occasional Paper 23: 1-628.

Hartmann-Schröder G. 1962. — Zur Kenntnis der Nereiden Chiles (Polychaeta Errantia), mit Beschreibung epitoker Stadien einiger Arten und der Jugendentwicklung von Perinereis vallata (Grube). Zoologischer Anzeiger 168 (11-12): 389-441.

HARTWICH G. 1993. — Die Polychaeten-Typen des Zoologischen Museums in Berlin. Mitteilungen aus dem Zoologischen Museum in Berlin 69: 73-154. https://doi.org/10.1002/mmnz.19930690106

HoAgLAND R. A. 1921. - Polychaetous annelids collected by the United States fisheries steamer Albatross during the Philippine expedition of 1907-1909. Bulletin of the United States National Museum 100 (1): 603-635. [Book cover publishing date states 1920, but volume published until 1921, see True \& Oesher (1947)]. https://library.si.edu/digital-library/book/bulletinunitedst10011928unit

Horst R. 1889. - Contributions towards the knowledge of the Annelida Polychaeta. Part 3. On species of Nereis, belonging to the sub-genus Perinereis. Notes from the Leyden Museum 11: 161186. http://direct.biostor.org/reference/ 147253

Horst R. 1919. - Three new Nereis-species from the Dutch East Indies. Zoologische Mededeelingen (Leiden) 5: 59-64. http://www. repository.naturalis.nl/document/150567

HORST R. 1924. - Polychaeta errantia of the Siboga Expedition. Pt. 3. Nereidae and Hesionidae. Siboga-Expeditie 24: 144-198.

Hutchings P. A., Reid A. \& Wilson R. S. 1991. - Perinereis (Polychaeta, Nereididae) from Australia, with redescriptions of six additional species. Records of the Australian Museum 43: 241274. https://doi.org/10.3853/j.0067-1975.43.1991.47

Hylleberg J., Nateewathana A. \& Bussarawit S. 1986. — Polychaetes of Thailand, Nereidae (Part 1), Perinereis and Pseudonereis, with notes on species of commercial value. Phuket Marine Biological Center Research Bulletin 43: 1-22.

ICZN (INTERNATIONAL COMMISSION ON ZOOLOGICAL NOMENCLATURE). 1999. - International Code of Zoological Nomenclature, 4th ed. International Trust for Zoological Nomenclature (The Natural History Museum), London, 306 p. http://iczn.org/iczn/ index.jsp (last consultation 28/10/2019).

JANSONIUS J. \& CRAIG J. H. 1971. — Scolecodonts: I. Descriptive terminology and revision of systematic nomenclature; II. Lectotypes, new names for homonyms, index of species. Bulletin of Canadian Petroleum Geology 19 (1): 251-302.

Jeldes F. 1963. - Un nuevo nereido de agua dulce para Chile. Gayana, Zoologia 9: 3-10. http://www.biodiversitylibrary.org/ item/91510\#page/223

KinBERG J. G. H. 1865. — Annulata nova. Nereidum dispositio nova. Öfversigt af Kongelige Vetenskaps-Akademiens Förhandlingar 22: 167-179. http://biostor.org/reference/105758

KinBERG J. G. H. 1910. - Kongliga svenska fregatten Eugenies resa omkring jorden under befäl af C. A. Virgin àren 1851-1853. Vetenskapliga iakttagelser. II, Zoologi. 3 Annulater. Kungliga Svenska Vetenskapsakademien, Stockholm, 78 p.

LAMARCK J. B. 1818. - Histoire Naturelle des animaux sans vertèbres, présentant les caractères généraux et particuliers de ces animaux, leur distribution, leurs classes, leurs familles, leurs genres, et la citation des principales espèces qui s'y rapportent; précédés d'une introduction offrant la détermination des caractères essentiels de l'animal, sa distinction du végétal et des autres corps naturels, enfin l'exposition des principes fondamentaux de la zoologie. Volume 5. Deterville, Paris, 612 p. https://www.biodiversitylibrary.org/item/46337\#page/7

LANGERHANS P. 1880. - Die Wurmfauna Madeiras. II. Zeitschrift für wissenschaftliche Zoologie 33 (1-2): 271-316. https://www. biodiversitylibrary.org/item/164138\#page/281

McIntosh W. C. 1910. - A monograph of the British Annelids, 2. Polychaeta. Syllidae to Ariciidae. Volume 2. Ray Society of
London, London, 291 p. https:/www.biodiversitylibrary.org/ item/118633\#page/13

PAIK E.-I. 1975. - Taxonomical evaluation of two varieties of Perinereis nuntia: P. nuntia var. vallata (Grube, 1857 ) and P. nuntia var. brevicirris (Grube, 1857). Bulletin of the Korean Fisheries Society 8 (4): 242-244.

Park T. S. \& KIM W. 2007. - A taxonomic study on Perinereis nuntia species group (Polychaeta: Nereididae) of Korea. Korean Journal of Systematic Zoology 23 (1): 75-85. https://doi.org/10.5635/ KJSZ.2007.23.1.075

PetERS W. 1881. - Beschreibungen von neuen Anneliden des zoologischen Museums zu Berlin. Sitzungsberichte der Gesellschaft der naturforschende Freunde zur Berlin 1881 (7): 109-117. https:// www.biodiversitylibrary.org/item/35574\#page/121

READ G. \& Fauchald K. 2018. — World Polychaeta database. Perinereis Kinberg, 1865. http://www.marinespecies.org/polychaeta/ aphia.php? $\mathrm{p}=$ taxdetails\&id $=129380$ (last consultation 28/10/2019)

Rozbaczylo N. \& Castilla J. C. 1973. - El género Perinereis (Annelida, Polychaeta, Nereidae) en Chile. Studies on the Neotropical Fauna 8: 215-232. https://doi.org/10.1080/01650527309360463 Salazar-Vallejo S. I., Carrera-Parra L. F., Muir A. I., De LeónGonzÁlez J. A., Piotrowski C. \& SATo M. 2014. — Polychaete species (Annelida) described from the Philippines and China Seas. Zootaxa 3842: 1-68. https://doi.org/10.11646/zootaxa.3842.1.1

SAmpértegui S., Rozbaczylo N., CANALES-Aguirre C. B., CARrasco F., Hernández C. E. \& Rodríguez-Serrano E. 2013. - Morphological and molecular characterization of Perinereis gualpensis (Polychaeta: Nereididae) and its phylogenetic relationships with other species of the genus off the Chilean coast, Southeast Pacific. Cahiers de Biologie Marine 54 (1): 27-40. https://doi. org/10.21411/CBM.A.6B64008A

SAVIGNY J. C. 1822. - Systèmes de diverses classes d'animaux sans vertèbres. Système des annélides, principalement de celles des côtes de l'Égypte et de la Syrie, offrant les caractères tant distinctifs que naturels des ordres, familles et genres, avec la description des espèces. Description de l'Égypte ou Recueil des Observations et des Recherches qui on été faites en Égypte pendant l'Expédition de l'Armée Française, publié par les Ordres de sa Majesté l'Empereur Napoléon le Grand, Histoire Naturelle, Paris 1 (3): 1-128. https:// doi.org/10.5962/bhl.title.66284

SCHMARDA L. K. 1861. - Neue wirbellose Thiere beobachtet und gesammelt aufeiner Reise um die Erde 1853 bis 1857. Erster Band: Neue Turbellarien, Rotatorien und Anneliden, Zweite Hälfte. Wilhelm Engelmann, Leipzig, 164 p. https://www.biodiversitylibrary. org/item/202417

SCHMARDA L. K. 1861b. - Reise um die Erde in den Jahre 18531857. Band 1-3. George Westermann, Braunschweig (Brunswick) [Volume 1, 592 p.; Volume 2, 501 p.; Volume 3, 518 p. https:// catalog.hathitrust.org/Record/008395733

Solís-Weiss V., Bertrand Y., Helléouet M. N. \& Pleijel F. 2004. - Types of polychaetous annelids at the Muséum national d'Histoire naturelle, Paris. Zoosystema 26 (3): 377-384.

Spalding M. D., Fox H. E., Allen G. R., Davidson N., Ferdaña Z. A., Finlayson M., Halpern B. S., Jorge M. A., Lombana A., Lourie S. A., Martin K. D., McManus E., Molnar J., RECCHIA C. A. \& RoBERTSON J. 2007. - Marine Ecoregions of the World: a bioregionalization of coast and shelf areas. BioScience 57: 573-583. https://doi.org/10.1641/B570707

True W. P. \& OESHER P. H. 1947. - A list and index of the publications of the United States National Museum (1875-1946), compiled in the Editorial Division, Smithsonian Institution. Bulletin of the United States National Museum 193: 1-306. https:// www.biodiversitylibrary.org/page/7687105

Villalobos-Guerrero T. F. \& CARRERA-PARRA L. F. 2015. — Redescription of Alitta succinea (Leuckart, 1847) and reinstatement of A. acutifolia (Ehlers, 1901) n. comb. based upon morphological and molecular data (Polychaeta: Nereididae). Zootaxa 3919 (1): 157-178. https://doi.org/10.11646/zootaxa.3919.1.7 
VON Frauenfeld G. R. 1856. - Naturhistorische Fragmente, gesammelt auf einer Reise am rothen Meere im Frühjahre 1855. Sitzungsberichte der Kaiserlichen Akademie der Wissenschaften. Mathematisch-Naturwissenschaftliche Classe 18 (1855): 66-86.

VON MARENZELler E. 1879. - Südjapanische Anneliden, 1. Amphinomea, Aphroditea, Lycoridea, Phyllodocea, Hesionea, Syllidea, Eunicea, Glycerea, Sternaspidea, Chaetopterea, Cirratulea, Amphictenea. Denkschriften der Mathematisch-Naturwissenschaftliche Classe der Kaiserlichen Akademie der Wissenschaften 41: 109-154. http://biostor.org/reference/67240

VON MARENZELLER E. 1888. - Polychäten der Angra Pequena-Bucht. Zoologische Jahrbücher, Abteilung für Systematik, Geographie und Biologie der Tiere 3 (1): 1-24. http://biostor.org/reference/181107

WeHE T. 2006. - Revision of the scale worms (Polychaeta: Aphroditoidea) occurring in the seas surrounding the Arabian Peninsula. Part I: Polynoidae. Fauna of Arabia 22: 23-197. http://www.libri. ch/App_Web/DE/services/faunaofarabia.aspx\#02

WesENBERG-Lund E. 1962. - Reports of the Lund University Chile Expedition 1948-49. 43. Polychaeta Errantia. Acta Universitets Årsskrift, Afdeling 2, 57 (12): 1-137.

WIKTOR J. 1980. — Type-specimens of Annelida Polychaeta in the Museum of Natural History of the Wroclaw University. Annales
Zoologici 35: 267-283.

Willey A. 1904. - Littoral Polychaeta from the Cape of Good Hope. Transactions of the Linnean Society of London, Series 2, Zoology9 (6): 255-268. https://doi.org/10.1111/j.1096-3642.1904. tb00450.x

WiLsON R. S. 1984. - Neanthes (Polychaeta: Nereididae) from Victoria with descriptions of two new species. Proceedings of the Royal Society of Victoria 96: 209-226.

WILSON R. S. 1993. - Systematics of the Perinereis nuntia complex (Polychaeta: Nereididae) from southeastern Australia. Records of the Australian Museum 45 (3): 241-252. https://doi.org/10.385 3/j.0067-1975.45.1993.22

Wilson R. S. \& Glasby C. J. 1993. - A revision of the Perinereis nuntia species group (Polychaeta: Nereididae). Records of the Australian Museum 45 (3): 253-277. https://doi.org/10.385 3/j.0067-1975.45.1993.23

Wu B. L., SUN R. \& YANG D. 1985 (first published in 1981 in Chineae). - The Nereidae (Polychaetous Annelids) of the Chinese coast. China Ocean Press, Beijing and Springer-Verlag Berlin Heidelberg, $234 \mathrm{p}$.

Yousefi S., Rahimian H., Nabavi S. M. B. \& Glasby C. J. 2011. Nereididae (Annelida: Polychaeta) from intertidal habitats in the Gulf of Oman, Iran. Zootaxa 3013: 48-64. 


\section{APPENDIX}

APPENDIX 1. - Type localities and collecting dates of the P. nuntia-like species collected by Schmarda, Kinberg, and von Martens.

The Austrian explorer and zoologist Ludwig Karl Schmarda set out a scientific circumnavigation to collect primarily invertebrates, but also vertebrates and plants (Wallaschek 2014). Schmarda began their journey leaving Trieste on early January 1853. He first went to Egypt, then to Ceylon, where he stayed from May 1853 to January 1854. Posteriorly, he went on to Cape Town (South Africa) via Mauritius (Troelstra 2016). Schmarda visited Cape Town from 20 February to 23 June 1854, where he studied mainly the marine invertebrates from Table Bay and Simonstown (Schmarda 1861). These may be regarded as the type localities and the collecting dates of most of his new polychaete species from the Cape of Good Hope, as for P. latipalpa n. comb. and many other nereidids.

After visiting the Cape, Schmarda settled about six months in Australia and New Zealand. He spent most of his time in the former country, but he stayed in the latter from 30 September to 2 November 1854 (Schmarda 1861). There, $N$. (Nereilepas) pacifica was collected in the Auckland harbor (Schmarda 1861), currently a supposed junior synonym of P. vallata (sensu Ehlers 1904, Hartman 1959). Later, Schmarda (1859, 1861) left Australia in late December 1854 and arrived to Chile in mid-March 1855. Despite Schmarda disembarked at Valparaiso, his somewhat deteriorated health forced him to visit firstly other continental landscapes. On his return, he resumed the marine zoological work in that city and partly in Vińa del Mar from 10 April to 15 May 1855 (Schmarda 1861). There he collected Nereis (Nereis) maculata Schmarda 1861 , which is currently regarded as a synonym of $P$. vallata (e.g. Hartmann-Schröder 1962). Next Schmarda devoted the rest of his expedition time in surveying material in other several American countries, such as Panama, Jamaica, Peru, Ecuador, Colombia, USA, Canada, and finally Cuba, which he reached in January 1857. From there, he departed to England and home, after a four-year journey (Schmarda 1859). The journey details were lately described in three volumes entitled Ludwig K. Schmarda's Reise um die Erde in den Jahre 1853-1857 (Schmarda 1861), although his activities in South Africa, Australia, New Zealand and Chile were dealt with in the second volume (Schmarda 1861).

The Schmarda's entire invertebrate collection did not endure the difficulties faced during the journey since $30-40 \%$ of his material was lost due to damage or losses in transportation or robberies (Schmarda 1859); nevertheless, type specimens of some polychaetes made it back (Augener 1925; Glasby \& Read 1998; personal observations). Schmarda was appointed as professor of zoology at the University of Vienna four years after returning from his journey, and hired afterward as head of the Natural History Museum in 1869 (at Bäckerstraße, Vienna), where his personal collection was formally deposited. Posteriorly, the museum and collections were transferred to the Zoological-Comparative-Anatomical Institute in 1883, housed in a novel building of the University of Vienna (at the Universitätsring), but Schmarda retired the next year.

In 1896, other collections were moved to the same building and merged into a Zoologisch-Vergleichend-Anatomische Sammlung (Zoological-Comparative-Anatomical collection) (Salvini-Plawen \& Mizzaro 1999). Later, some of the Schmarda's marine invertebrate specimens, if not all, were transferred to the Naturhistorisches Museum Wien (Natural History Museum Vienna, NHMW) as a gift from the University of Vienna; however, some of the acquisitions lists of the Evertebrata varia collection have got lost during the World War II (H. Sattmann pers. com. 2016). It is possible that Schmarda's collection arrived at the NHMW in 1929 according to acquisitions records of nemerteans (Senz 2003), crustaceans (H. Sattmann pers. com. 2018), and even reptiles (Tiedemann et al. 1994) which are still available at the museum. Thus, the above mentioned may explain the older and recent labels imprints of $N$. latipalpa's lots (Fig. 3A); the former with the Zoologisch-Vergleichend-Anatomische Sammlung marks, whereas the latter typewritten in Latin with the coll. Musei Vindobonensis, Evertebrata varia labeling, which refers to the current collection of "Invertebrates other than Arthropoda, Mollusca, Tentaculata and Chordata" at the NHMW.

The Swedish veterinarian Johan G. H. Kinberg was selected as a zoologist and senior physician of a scientific expedition around the world in the frigate Eugenie during 1851-1853, where he gathered a worthy collection of animals, mainly of marine invertebrates (Persson 1971, Franzén 1975-1977). The frigate travelled to several islands in the Atlantic, Pacific and Indian Ocean, also reached Brazil, Argentina, Uruguay, Chile, Peru, Ecuador, Panama, West USA, Australia, China, Indonesia, and South Africa. For the latter, the expedition visited the Table Bay, Cape Town from 8 to 20 April 1853 (Andersson 1854). These may be regarded as the type locality and the collecting date of his new polychaete species from the "Cap". There, Kinberg collected Neanthes latipalpa, a junior synonym of $P$. latipalpa n. comb.

The German zoologist Karl Eduard von Martens, who in 1859 became curator of invertebrates at the Museum für Naturkunde Berlin (ZMB), travelled on the frigate Thetis on the Prussian Expedition to East Asia in 1860-1862 to collect scientific material. von Martens left the Thetis in Singapore from where he made an independent collecting trip around the Indo-Australian Archipelago from March 1862 to December 1864 (Hoppe 1990; Bauer 2016). Among the visited localities, von Martens devoted some time collecting material in Flores (currently as East Flores Regency), particularly in Solor, Adonara, and Larantuka from 6 to 30 January 1863 (von Martens 1876). This is, in fact, the most accurate collecting date of $P$. larentukana n. comb., herein regarded as a member of the $P$. nuntia species complex. 


\section{REFERENCES}

ANDERSSON N. J. 1854. - En verldsomsegling skildrad i bref af $N$. $J$. Andersson, naturforskare under expeditionen med fregatten Eugenie åren 1851, 1852 och 1853. Tredje delen. Australien, Kina, Ost-Indien och Cap. Hos Samson \& Wallin, Stockholm, 388 p.

Augener H. 1925. - Über westindische und einige andere PolychaetenTypen von Grube (Oersted), Krøyer, Mörch und Schmarda. Publikationer fra Universitetets Zoologiske Museum Kobenhavn 39: 1-47.

Bauer A. M. 2016. - Southeast Asian and Australasian Herpetological collections from the eighteenth and nineteenth centuries in the Zoological Museum of Berlin, in DAS I. \& TUEN A. A. (eds), Naturalists, Explorers and Field Scientists in South-East Asia and Australasia. Topics in Biodiversity and Conservation, Volume 15. Springer International Publishing, Switzerland: 89-108. https:// doi.org/10.1007/978-3-319-26161-4_6

EHLERS E. 1904. — Neuseeländische Anneliden. Abhandlungen der Königlichen Gesellschaft der Wissenschaften zu Göttingen Mathematisch-Physikalische Klasse. Neue Folge 3 (1): 1-80. http:// biostor.org/reference/144682

FrANZÉN O. 1975-1977. - JG Hjalmar Kinberg. Svenskt biografiskt lexikon, Band 21: 148. https://sok.riksarkivet.se/sbl/artikel/11490 (last consultation 28/10/2019).

Glasby C. J. \& READ G. B. 1998. - A chronological review of polychaete taxonomy in New Zealand. Journal of The Royal Society of New Zealand 28 (3): 347-374. https://doi.org/10.1080/0301 4223.1998 .9517570

HaRTMAn O. 1959. - Catalogue of the Polychaetous Annelids of the World. Allan Hancock Foundation Publications, Occasional Paper 23: 1-628.

HARTMANN-SchrÖder G. 1962. - Zur Kenntnis der Nereiden Chiles (Polychaeta Errantia), mit Beschreibung epitoker Stadien einiger Arten und der Jugendentwicklung von Perinereis vallata (Grube). Zoologischer Anzeiger 168 (11-12): 389-441.

Hoppe B. 1990. - Martens, Eduard von. Neue Deutsche Biographie 16, S. $268 f$. https://www.deutsche-biographie.de/pnd120818922. html\#ndbcontent
PERSSON P. I. 1971. — “Eugenies resa”. Localities, dates and labels of the insects collected during the voyage around the world by the Swedish frigate "Eugenie" in the years 1851-1853. Entomologisk Tidskrift 92 (3-4): 164-172.

SALVini-PLAWEN L. \& MizZARO M. 1999. — 150 Jahre Zoologie an der Universität Wien. Verhandlungen der Zoologisch-Botanischen Gesellschaft in Österreich 136: 1-76.

SCHMARDA L. K. 1859. - Neue wirbellose Thiere beobachtet und gesammelt auf einer Reise um die Erde 1853 bis 1857. Erster Band: Neue Turbellarien, Rotatorien und Anneliden. Erste Hälfte. Wilhelm Engelmann, Leipzig, 66 p. https://www.biodiversitylibrary. org/item/162010

SCHMARDA L. K. 1861. - Reise um die Erde in den Jahre 18531857. Band 1-3. George Westermann, Braunschweig (Brunswick) [Volume 1, 592 p.; Volume 2, 501 p.; Volume 3, 518 p. https:// catalog.hathitrust.org/Record/008395733 (last consultation 28/10/2019).

SENZ W. 2003. - Katalog der Nemertinea in der Evertebrata VariaSammlung, nach dem Stand von 1.1. 2003. Kataloge der wissenschaftlichen Sammlungen, Evertebrata Varia, Band 17, Heft 2. Naturhistorischen Museums, Wien, 48 p.

Tiedemann F., Häupl M. \& Grillitsch H. 1994. - Katalog der Typen der herpetologischen Sammlung nach dem Stand vom 1. Jänner 1994. Teil II: Reptilia. Kataloge der wissenschaftlichen Sammlungen, Vertebrata, Band 10, Heft 4. Naturhistorischen Museums, Wien, 102 p.

Troelstra A. S. 2016. - Bibliography of natural history travel narratives. KNNV Publishing, Zeist, $482 \mathrm{p}$.

Von Martens E. 1876. - Die Preussische Expedition nach Ost-Asien. Nach amtlichen Quellen. Zoologischer Teil. Erster Band. Allgemeines und Wirbelthiere. Verlag der Königlichen Geheimen Ober-Hofbuchdruckerei (R. v. Decker), Berlin, 412 p. http://www.rhinoresourcecenter.com/index. php? $=1$ \&act $=$ refs \&CODE $=$ ref_detail \&id $=1165237909$ (last consultation 28/10/2019).

WALLASCHEK M. 2014. - Ludwig Karl Schmarda (1819-1908): Leben und Werk. Halle, Saale, 142 p. 